\title{
On the use of NDT data for reliability-based assessment of
}

\section{existing timber structures}

Hélder S. Sousa, ${ }^{\mathrm{a}, *}$, John D. Sørensen ${ }^{\mathrm{b}}$, Poul H. Kirkegaard ${ }^{\mathrm{b}}$, Jorge M. Branco ${ }^{\mathrm{a}}$, Paulo B. Lourenço ${ }^{\mathrm{a}}$

\author{
${ }^{\text {a }}$ Department of Civil Engineering, ISISE, University of Minho, Portugal \\ ${ }^{\mathrm{b}}$ Department of Civil Engineering, Aalborg University, Denmark \\ * corresponding author: ISISE, University of Minho \\ Department of Civil Engineering, Azurém, \\ 4800-058 Guimarães, Portugal \\ e-mail: hssousa@civil.uminho.pt \\ Tel: +351 253510200; Fax: +351253510217
}

\begin{abstract}
The objective of this paper is to address the possibilities of using non-destructive testing (NDT) data for updating information and obtaining adequate characterization of the reliability level of existing timber structures and, also, for assessing the evolution in time of performance of these structures when exposed to deterioration. By improving the knowledge upon the mechanical properties of timber, better and more substantiated decisions after a reliability safety assessment are aimed at.

Bayesian methods are used to update the mechanical properties of timber and reliability assessment is performed using First Order Reliability Methods (FORM). The results show that different degrees of belief in the updating data may significantly influence the reliability level. The updating data to be used are NDT results obtained with ultrasound, resistance drilling and pin penetration equipments. The tests were conducted on chestnut wood (Castanea sativa Mill.) specimens, and were combined with tests to determine the compressive strength parallel to the grain. The uncertainty of the different NDT results is modeled by Maximum Likelihood estimates. Resistance distributions functions are considered to analyze the difference before and after updating by NDT, showing that lower variations may typically be obtained with the new information. Moreover, updating of the parameters in different deterioration models is considered in order to be able to evaluate the time dependency of the reliability, and information of NDT is also used to calibrate these models.

The proposed approach is used for reliability assessment of different structural timber systems. Reliability of the structural system is assessed regarding the failure consequences of individual elements defined as key elements which were determined by their influence on the cross section loss.
\end{abstract}


The results given by the pin penetration tests were the most similar to the reference experimental model with statistic parameters given by the results of destructive tests. The resistance drilling and ultrasound updating schemes led to higher level of reliability than the reference model values, therefore these updating data should be considered with caution, as they can result in unsafe results for the reliability compared to the reference models.

Keywords: Timber structures; NDT; Assessment; Reliability; Updating methods

\section{NOTATION:}

Latin upper case letters:

$A$ - area

COV - coefficient of variation

DT - destructive tests

$E$ - expected value

$E_{\text {dyn }}$ - dynamic modulus of elasticity

$G$ - permanent load

$G_{\mathrm{k}}$ - characteristic value for permanent load

$M_{\mathrm{i}}$ - safety margin

NDT - non-destructive testing

$P_{\mathrm{f}}^{P}$ - probability of failure of a parallel system

$P_{\mathrm{f}}^{\mathrm{S}}$ - probability of failure of a series system

$Q$ - variable load

$Q_{\mathrm{k}}$ - characteristic value for variable load

$R$ - resistance function

$R M$ - drilling resistance indicator

$X$ - stochastic variable

Latin lower case letters:

$a$ - square cross section size

$b$ - width

$f_{\mathrm{c}, 0}$ - compressive strength parallel to grain

$f_{\mathrm{m}}$ - bending strength

$f_{\mathrm{m}, \mathrm{k}}$ - characteristic bending strength

$f_{\mathrm{N}}($ ) - likelihood function

$f_{\mathrm{Q}^{\prime}}(\mathrm{)})$ - prior density function

$f_{\mathrm{Q}}{ }^{\prime \prime}()$ - posterior density function

$f_{\mathrm{X}}(\mathrm{)}$ - density function $g$ - limit state equation

$g_{\mathrm{i}}()$ - failure function

$h$ - heigth

$k_{\text {climate }}$ - parameter of climate conditions

$k_{\text {mod }}$ - modification factor

$k_{\text {wood }}$ - parameter of timber durability class

$l$ - length

$m$ - sample mean

$m^{\prime}$ - prior function hypothetical sample average

$m^{\prime \prime}$ - posterior function hypothetical sample average

$n$ - number of tests

$n^{\prime}$ - prior function hypothetical number of observations for $m^{\prime}$

$n^{\prime \prime}$ - posterior function hypothetical number of observations for $m^{\prime}$

$p_{\mathrm{f}}$ - probability of failure

$q$ - vector of distribution parameters

$r$ - penetration rate

$s$ - sample standard deviation

$s^{\prime}$ - prior function hypothetical sample value

$s^{\prime \prime}$ - posterior function hypothetical sample value

$t_{v^{\prime \prime}}$ - central $t$-distribution value

$t_{\text {lag }}$ - time between construction and the point that noticeable decay commences

$v^{\prime}$ - prior function hypothetical number of degree of freedom for $s^{\prime}$ 
$v^{\prime \prime}$ - posterior function hypothetical number of degree of freedom for $s^{\prime}$

$\hat{x}$ - sample of realizations

Greek lower case letters:

$\alpha$ - factor for modeling the fraction of variable load

$\alpha_{\mathrm{i}}$ - regression parameter

$\beta$ - reliability index

$\gamma_{\mathrm{G}}$ - partial safety factor for permanent loads

$\gamma_{m}$ - partial safety factor for material properties

$\gamma_{Q}$ - partial safety factor for variable loads
$\mathcal{E}$ - lack-of-fit

$\lambda$ - failure rate

$\lambda_{\text {rel }}$ - slenderness ratio

$\mu$ - mean value

$\mu_{\text {depth }}$ - average of pin penetration tests

$\mu_{\mathrm{DT}}$ - average of destructive tests

$\mu_{\text {Edyn }}$ - average of ultrasound tests

$\mu_{\mathrm{RM}}$ - average of resistance drilling tests

$\sigma$ - standard deviation

$\tau$ - perimetral loss of cross-section

\section{INTRODUCTION}

The assessment of existing timber structures encounters several difficulties. Both timber elements and joints must be characterized, and both the present state of conservation and the evolution in time of performance must be considered [1]. In situ inspection by means of visual inspection and nondestructive testing (NDT) provides a first step towards diagnosis of damage, structural analysis and safety assessment. This initial survey is mostly aimed at defining qualitatively the state of conservation and structural condition, and laboratory tests of extracted specimens would be desirable to study the variability of the mechanical properties of the timber elements [2], [3]. Nevertheless, in many cases, the mechanical properties of timber elements may only be assessed by visual inspection or by NDT, without any possibility to collect specimens or by obtaining only a very limited number of samples. Therefore, several authors have considered the combination of visual inspection and NDT for the assessment of the mechanical properties of timber (see e.g. [4], [5])

Although visual strength grading of existing timber may be applicable in most cases with reasonable results, it may also be difficult, or even impossible [6], and it may lead to over-conservative predictions of the mechanical properties, despite the significant research on NDT in the last decades [7]. One way to improve the accuracy of the estimation of the mechanical properties of timber is to carry out a cross-validation of the information gathered by the application of different non-destructive and semi-destructive techniques [8], [9], and also its correlation with destructive tests (see e.g. [10]).

Over the past years, several guidelines and recommendations on how to approach the inspection and maintenance of existing timber structures have been suggested [11], [12] but further standardization and objectivity is desired. ISO 13822:2001 [13] provides a framework for the assessment of existing structures aiming at determining structural safety and optimizing costs. At national level, ASCE 11-99 [14] addresses the structural condition assessment of different structures, including timber buildings, 
whereas the Italian standards UNI 11119:2004 [15] and UNI 11138:2004 [16] deal with the inspection and diagnosis of cultural heritage timber structures. Guidelines for assessment criteria of load bearing timber structures in heritage buildings, with special emphasis in visual inspection, are presented in [17].

In addition to the difficulties in assessing existing timber elements, high variability in the mechanical and physical properties of wood occur due to the influence of natural growth defects, such as knots and fiber misalignment. This variability combined with the uncertainty of NDT results makes structural assessment based on full probabilistic methods (reliability methods) desirable. These methods allow a clearer definition of randomness and reliability, when compared to deterministic or semi-probabilistic methods [18]. This is of special interest in the assessment of existing structures where different levels of assessment analysis or a less accurate reliability evaluation may result in no-required repair actions, over conservative strengthening, replacement of elements or restriction of loading (e.g. [19],[20]). During the last decades, structural reliability methods have been refined and are presently at a stage such that they can be used in engineering applications. ISO 2394:1998 [21] and EN 1990:2002 [22] consider full probabilistic methods as acceptable procedures for structural assessment. Structural reliability may be defined as the probability of a limit state function being violated [23] and target reliability indices are established considering different consequences classes, reference periods of time and relative cost of safety measures [22]. When assessing an existing structure, in situ inspection can be made, which cannot be considered for designing a new structure. However, increasing the reliability level for an existing structure can be more expensive than when designing a new structure [24].

Probabilistic models for timber have been proposed by several authors [25], [26] and are implicitly defined in various codes and guidelines, and the properties can be updated from mechanical tests [22] [27]. These models allow serviceability [28] and structural reliability evaluation [29], [30]. In an existing building estimates from the design phase can be replaced by information gathered in the actual structure allowing for better maintenance, repair and strengthening [31]. The assessment of structural performance is dependent on the capacity to evaluate the physical and mechanical properties of structural timber elements, thus the interest in updating the material properties by use of visual inspection and NDT.

A grading methodology based on visual inspections associated with NDT results is a suitable source of information for updating stochastic models, and thereby the probability of failure. For that purpose, Bayesian methods, e.g. [32], are often applied to include new information into the probabilistic assessment due to their simplicity of use and possibility of expressing different degrees of belief to a given information in form of probability distributions [33], [34], [35]. That degree of belief, defined as a priori information, provides a judgment on plausibility of the values of model parameters. Due to its subjective nature, the selection of the prior probability distribution is controversial [36]. Bayesian 
methods allow quantifying the uncertainty related to the estimated parameters, regarding the physical uncertainty of the variables, as well as the statistical uncertainty of the model parameters and the model uncertainty of the applied mathematical model. The application of Bayesian inference to the evaluation of the modulus of elasticity in bending of maritime pine and chestnut timber, attained by visual strength grading combined with information from NDT, demonstrates that a more unbiased prediction can be found compared to classical inference where a random variable is characterized solely by using data from an experiment [37].

In the assessment of the reliability level of an existing timber structure, the decay/degradation activity should be considered. Timber is highly dependent of the climatic conditions of the surrounding environment and the attack of pathological agents depends on wood moisture contents, temperature and solar exposure. Often NDT is used for assessing the conservation status and level of deterioration ([30], [38]).

The present paper aims at discussing the influence of NDT data in the reliability-based assessment of existing timber structures when using prior information together with new information. By improving the knowledge upon the mechanical properties of timber, it is aimed to allow for better and more substantiated decisions after a reliability safety assessment. It is noted that in most cases application of more data will result in a higher updated reliability, but in some cases where the prior information was too optimistic a lower reliability may be the result. However, in both cases decisions on further inspections/repair can be made on a better and more informed basis. For this purpose, results gathered from NDT by ultrasound resistance drilling and pin penetration tests, conducted on chestnut wood (Castanea sativa Mill.) are used. The wood sample used for NDT was also tested to obtain the compressive strength parallel to grain, and the subsequent correlations are considered [39]. The uncertainties of NDT methods are modeled through Maximum Likelihood where the estimates are included in the reliability assessment. First order reliability methods are used for reliability assessment with the inclusion of Bayesian updating. The framework for assessment is described using practical examples regarding single element structures and a truss system, subjected to bending and compression parallel to grain, respectively. Decay is assumed by a cross section loss and its influence in structural reliability is also modeled, and is applied to key elements of the structure, allowing for an evaluation of reliability in time.

\section{METHODOLOGY}

\subsection{Structural system}

When evaluating the reliability level of an existing structure it is important to assess which are the most likely failure modes and to identify which are the key elements. A key element is such that, if failing, would result in extensive failure or progressive collapse of the structure. Therefore, data regarding these elements will prove more important in an updating scheme, since the information will 
directly change the reliability level of the structural system. After determining the key elements of a structure, the failure sequences must be defined. In this case, a failure sequence corresponds to the succession of individual element failures that will produce a system failure. The probability of failure of a structure is determined by the difference between the resistance distribution (capacity) and the load effect distribution (demand). The basics of this theory are detailed in [23], [40], [41]. If the structure can be modeled by a series system, then the failure of one (key) element implies failure of the system. Using a FORM approximation to assess the structural reliability, a safety margin $M_{i}$ is assumed to be formulated for each of the $m$ failure modes [42]:

$$
M_{\mathrm{i}}=g_{\mathrm{i}}(X), i=1,2, \ldots, m
$$

where $g_{\mathrm{i}}(X)$ is the failure function related to failure mode $i$. The uncertain parameters are modeled by the stochastic variables $X$. The probability of failure of the series system, $P_{\mathrm{f}}^{S}$, is defined by:

$$
P_{\mathrm{f}}^{\mathrm{S}}=P\left(\bigcup_{i=1}^{m}\left\{M_{\mathrm{i}} \leq 0\right\}\right)=P\left(\bigcup_{i=1}^{m}\left\{g_{\mathrm{i}}(X) \leq 0\right\}\right)
$$

If the structure or a part of it can be modeled by a parallel system (e.g. a sequence of elements whose failure implies failure of the structure), then all $n$ elements have to fail before failure of the system. In this case the probability of failure, $P_{\mathrm{f}}^{P}$ can be estimated by:

$$
P_{\mathrm{f}}^{\mathrm{P}}=P\left(\bigcap_{\mathrm{i}=1}^{\mathrm{n}}\left\{M_{\mathrm{i}} \leq 0\right\}\right)=P\left(\bigcap_{\mathrm{i}=1}^{\mathrm{n}}\left\{g_{\mathrm{i}}(X) \leq 0\right\}\right)
$$

In this work, reliability analysis using FORM was performed with PRADSS [43].

\subsection{Initial structural characterization}

For an existing structure, an initial reliability assessment should be performed corresponding to the original conditions of the structure. For that assessment, information about the structure may be given directly from the designer's structural plans, calculations and/or material specifications. However, not always this information is available and therefore indicative values may be found for material properties in standards, often based on semi-empirical information, and from a geometrical survey. This initial analysis is important in order to establish prior information on the structural behavior and level of reliability. Here, it is proposed to assess first the design phase using the ultimate limit state equations in standards, such as [44]. Indicative material properties can be obtained from [27] and [45] for probabilistic and semi-deterministic reliability analysis. 


\subsection{Updating methodology}

\subsubsection{Bayesian updating of reliability}

When samples or measurements of a stochastic variable $X$ are provided, the probabilistic model may be updated and, thus, also the probability of failure. In case $X$ represents a basic material property, the new information might be used to improve any prior estimate of the material property. This information may be differentiated taking into consideration its source, namely from being direct (measurements of the material property) or indirect information (measurements of some indicators of the property) [26].

It is assumed a stochastic variable $X$ with density function $f_{\mathrm{X}}(x)$. If $q$ denotes a vector of parameters defining the distribution for $X$, the density function can be rewritten as $f_{\mathrm{X}}(x, q)$. When the parameters $q$ are uncertain, $f_{\mathrm{X}}(x, q)$ can be considered as a conditional density function: $f_{\mathrm{X}}(x \mid Q=q)$, where $q$ denotes a realization of $Q$. Therefore $q$ is a vector of distribution parameters, such as the mean value $\mu$ and standard deviation $\sigma$. The initial density function for the parameters $Q$ is $f_{\mathrm{Q}}{ }^{\prime}(q)$ and is named the prior density function.

Taking into account new information, it is assumed that $n$ observations or measurements of the stochastic variable $X$ are available making up a sample $\hat{x}=\left(\hat{x}_{1}, \hat{x}_{2}, \ldots, \hat{x}_{\mathrm{N}}\right)$. If these measurements are assumed to be statistically independent, the updated (posterior) density function $f_{\mathrm{Q}}^{\prime \prime}(q \mid \hat{x})$ of the uncertain parameters $Q$ given the realizations is named the posterior density function and is given by:

$$
f_{\mathrm{Q}}^{\prime \prime}(q \mid \hat{x})=\frac{f_{\mathrm{N}}(\hat{x} \mid q) f_{\mathrm{Q}}^{\prime}(q)}{\int f_{\mathrm{N}}(\hat{x} \mid q) f_{\mathrm{Q}}^{\prime}(q) \mathrm{dq}}
$$

where the likelihood function $f_{\mathrm{N}}(\hat{x} \mid q)=\prod_{\mathrm{i}=1}^{\mathrm{N}} f_{\mathrm{X}}\left(\hat{x}_{\mathrm{i}} \mid q\right)$ is the probability density of the given observations assuming that the distribution parameters are $q$. The updated (predictive) density function of the stochastic variable $X$ given the realization $\hat{x}$ is named the predictive density function and is defined by:

$$
f_{\mathrm{X}}(x \mid \hat{x})=\int f_{\mathrm{X}}(x \mid q) f_{\mathrm{Q}}^{\prime \prime}(q \mid \hat{x}) \mathrm{dq}
$$

The prior and posterior distributions are chosen according to the available data and to the importance of the analysis. Closed form solutions for the predictive and the posterior distribution can be found for several probability functions, in e.g. [46]. These solutions contemplate a number of distribution types which are common in structural engineering reliability. Normal distributions are often used to exemplify the updating process (e.g. [11]) which is presented hereafter. Assuming that $X$ follows a normal distribution and that the mean value $\mu$ and standard deviation $\sigma$ are unknown, the prior distribution of the resistance function $R$ is given by $f_{\mathrm{Q}}{ }^{\prime}(q)=f_{\mathrm{R}}{ }^{\prime}(\mu, \sigma)$ and can be defined as [47]: 


$$
f_{\mathrm{R}}^{\prime}(\mu, \sigma)=k \sigma^{-\left(v^{\prime}+\delta\left(n^{\prime}\right)+1\right)} \exp \left(-\frac{1}{2 \sigma^{2}}\left(v^{\prime}\left(s^{\prime}\right)^{2}+n^{\prime}\left(\mu-m^{\prime}\right)^{2}\right)\right)
$$

with $\delta\left(n^{\prime}\right)=0$ for $n^{\prime}=0$ and $\delta\left(n^{\prime}\right)=1$ for $n^{\prime}>0$. The prior information about the standard deviation $\sigma$ is given by parameters $s^{\prime}$ and $v^{\prime}$. The expected value $E(\sigma)$ and Coefficient of Variation $\operatorname{COV}(\sigma)$ of $\sigma$ can asymptotically (for large $v^{\prime}$ ) be expressed as:

$$
\begin{gathered}
E(\sigma)=s^{\prime} \\
\operatorname{Cov}(\sigma)=\frac{1}{\sqrt{2 v^{\prime}}}
\end{gathered}
$$

The prior information about the mean $\mu$ is given by parameters $m^{\prime}, n^{\prime}$ and $s^{\prime}$, and the expected value $E(\mu)$ and coefficient of variation $\operatorname{COV}(\mu)$ of $\mu$ can asymptotically (for large $v^{\prime}$ ) be expressed as:

$$
\begin{gathered}
E(\mu)=m^{\prime} \\
\operatorname{Cov}(\mu)=\frac{s^{\prime}}{m^{\prime} \sqrt{n^{\prime}}}
\end{gathered}
$$

Another possible way to interpret the prior information is to consider the results of a hypothetical prior test series for mean and standard deviation analysis. For that case, the standard deviation is characterized by $s^{\prime}$ (hypothetical sample value) and $v^{\prime}$ (hypothetical number of degrees of freedom for $s^{\prime}$ ). The information about the mean is given by $m^{\prime}$ (hypothetical sample average) and $n^{\prime}$ (hypothetical number of observations for $m$ ').

Usually the degrees of freedom for the number of observations $n$ is given by $v=n-1$, but the prior parameters $n^{\prime}$ and $v^{\prime}$ are independent from each other. When new information is available, the resistant model given by the prior distribution $f_{\mathrm{R}}{ }^{\prime}(\mu, \sigma)$ may be updated according to Eq. (4), with the parameters:

$$
\begin{gathered}
n^{\prime \prime}=n^{\prime}+n \\
v^{\prime \prime}=v^{\prime}+v+\delta\left(n^{\prime}\right) \\
m^{\prime \prime} n^{\prime \prime}=n^{\prime} m^{\prime}+n m \\
v^{\prime \prime}\left(s^{\prime \prime}\right)^{2}+n^{\prime \prime}\left(m^{\prime \prime}\right)^{2}=v^{\prime}\left(s^{\prime}\right)^{2}+n^{\prime}\left(m^{\prime}\right)^{2}+v s^{2}+n m^{2}
\end{gathered}
$$

With this procedure the predictive value of the resistance $R$ is given by: 


$$
f_{\mathrm{R}}=m^{\prime \prime}-t_{v^{\prime \prime}} s^{\prime \prime} \sqrt{\left(1+\frac{1}{n^{\prime \prime}}\right)}
$$

where $t_{v^{\prime \prime}}$ has a central t-distribution [47].

The new information may be obtained from the data gathered with non-destructive tests, meaning that reliability may be updated.

In the case studies presented in this work, lognormal distributions were considered for the predictive and posterior distributions when considering variables related to resistance parameters.

\subsubsection{Updating data for timber}

Timber may be graded using different principles but mechanical properties are usually defined by correlations with other characteristics, e.g. [27]. NDT allows to obtain indications about mechanical properties through correlations with laboratory tests, e.g. [3], [10], [39]. Another method to address the variability of wood properties is to use known values rather the values obtained from the direct (or even indirect) measurements [48]. In any case, for existing structures, as new information become available, for example from NDT correlations, the mechanical properties of the structural elements may be updated. The choice of updating parameters and of its physically justified range (variation bounds) is one of the most important aspects of an updating process. As mentioned in Mares et al. [36], the variances and covariances of the inputs should be updated together with the mean values, and if the prior knowledge about an input is sparse, the corresponding variance will be large. In this case, during the updating process, the resulting posterior variance should decrease as a result of increasing the amount of knowledge on the input. If the change in an updated input and its posterior variance are small, the output data is insensitive to it and, therefore, a different parameterization must be used.

In this paper, Bayesian methods are used to update the mechanical properties of the material and the parameters of deterioration models. The updating data was obtained through NDT results collected using indirect methods, namely ultrasound, resistance drilling and pin penetration testing, conducted upon chestnut wood (Castanea sativa Mill.) specimens. Moreover, mechanical tests results were used to establish correlations between NDT results and the compressive strength parallel to grain, $f_{\mathrm{c}, 0}$. The data was gathered in [39] and are shown in Figure 1. Here, the drilling resistance indicator $(R M)$ represents the ratio between the integral of the area of the diagram given by the resistance drilling equipment divided by the drilling length. For the case of the pin penetration tests, the considered indicator parameter is the needle penetration depth taken directly from the tests. For the ultrasound tests the dynamic modulus of elasticity $\left(E_{\mathrm{dyn}}\right)$ is adopted. 


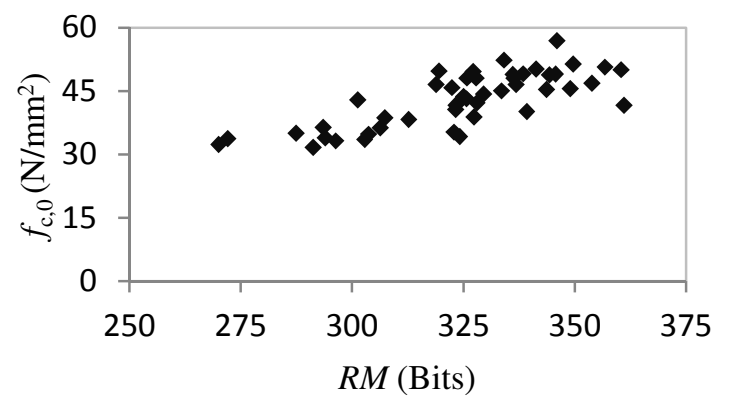

a)

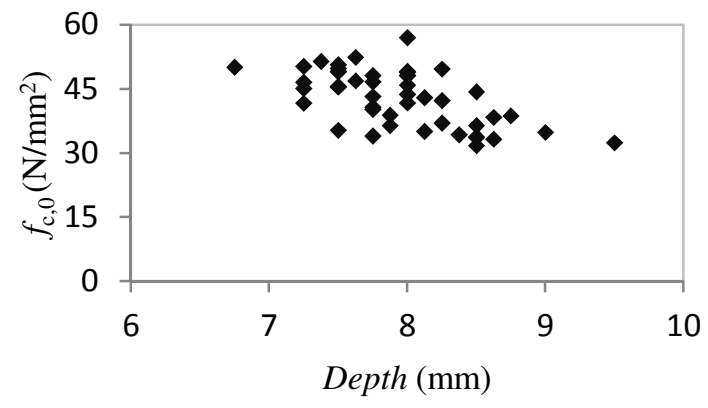

b)

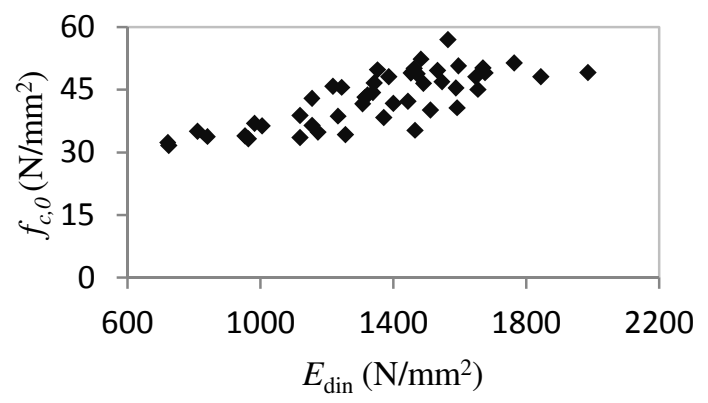

c)

Figure 1 - Correlation information between $f_{\mathrm{c}, 0}$ and NDT results for chestnut wood [39]:

a) resistance drilling; b) pin penetration; c) ultrasound.

The uncertainties associated to the NDT methods are modeled and included in the reliability assessment through a Maximum Likelihood fit of the parameters using a linear regression model [25] of the dependency between $f_{\mathrm{c}, 0}$ and the considered indicator. The following general regression model in $x_{1}, \ldots, x_{\mathrm{m}}$-space was considered:

$$
y=\alpha_{0}+\alpha_{1} x_{1}+\ldots+\alpha_{\mathrm{m}} x_{\mathrm{m}}+\varepsilon
$$

where $\alpha_{0}, \alpha_{1}, \ldots, \alpha_{\mathrm{m}}$ are the regression parameters and the parameter $\varepsilon$ models the lack-of-fit.

The model uncertainty is modeled by $\varepsilon$ and by assuming that it follows a normal distribution with expected value zero and unknown standard deviation $\sigma_{\varepsilon}$, the Maximum Likelihood method may be used to estimate the mean values and covariance matrix for parameters $\alpha_{\mathrm{m}}$ and $\sigma_{\varepsilon}$. Physical uncertainty, in this case regarding the compression parallel to grain values, can be modeled by parameters $x_{1}, \ldots, x_{\mathrm{m}}$ that are measured during the tests but may be considered as stochastic variables in the reliability analysis. Indications for selecting suitable probabilistic models for material and geometric models are given in [49]. Statistical uncertainty, originated due to reliance on limited information and finite samples, can be modeled by considering the mean and standard deviation of $\varepsilon$ as stochastic variables and by estimating its covariance. Measurement uncertainty was not included in this model, however may be added by estimating the uncertainty that may arise from random and systematic errors in the measurement of the physical quantities. The regression parameters for the dependency between $f_{c, 0}$ and the NDT indicators were calculated using the data gathered in [39] and are given in Table 1. 
Table 1 - Regression parameters and lack-of-fit standard deviation for the non-destructive tests results as a dependency of the compression strength $f_{\mathrm{c}, 0}$.

\begin{tabular}{llccc}
\hline & & $\boldsymbol{a}_{\mathbf{0}}$ & $\boldsymbol{a}_{\mathbf{1}}$ & $\boldsymbol{\sigma}_{\varepsilon}$ \\
\hline Resistance drilling $[\mathrm{RM}]$ & $(\mathbf{B i t s})$ & -30.69497 & 0.22750 & 4.12217 \\
Pin penetration $[\mathrm{depth}]$ & $(\mathbf{m m})$ & 102.59179 & -7.50664 & 5.12435 \\
Ultrasound $\left[\mathrm{E}_{\mathrm{dyn}}\right]$ & $\left(\mathbf{N} / \mathbf{m m}^{2}\right)$ & 19.24686 & 0.01761 & 4.06081 \\
\hline
\end{tabular}

\subsection{Deterioration models}

Stewart and Hong [50], when discussing steel corrosion in concrete, mention that design standards are conservative and are not best suited for predicting structural performance, particularly when the structural components suffer degradation in time. The same consideration can be made for existing timber structures [51] and several efforts have been made to implement probabilistic procedures for decay assessment in these structures [29] and to consider the aging effects regarding deterioration [52].

Here, a two-parameter idealized decay model, based in empirical evidences, was considered to assess the evolution of deterioration [53], defined by:

$$
t_{\mathrm{lag}}=3 \cdot r^{-0.4}
$$

The parameters are the period of time between construction and the point that noticeable decay commences, $t_{\text {lag }}$ (year), and the annual penetration rate, $r(\mathrm{~mm} / \mathrm{year}$ ), see Figure 2. In Wang et al. [54] it is proposed to define the penetration rate as a function of different climatic conditions, $k_{\text {climate, }}$, and of the timber durability class, $k_{\text {wood }}$, given by:

$$
r=k_{\text {climate }} \cdot k_{\text {wood }}
$$

Considering a probabilistic analysis, the $r$ parameter is modeled by a lognormal distributed stochastic variable with a COV between 0.85 and 1.2 depending on the timber durability class and climatic conditions [54]. The $t_{\text {lag }}$ parameter is defined as function of the penetration rate [54], [55].

Other decay models based on observation could also be used, with due care regarding the reliability of information and amount of data.

In Nguyen et al. [55] also the size and orientation of the cross section, the presence of connectors and existence of painting is considered, being possible to obtain different penetration rates for each side of the element. The use of decay models with different penetration rates for each side of the element considering the directional orientation of the decay surface and location of the cross section in the structure has also been considered in [29], [56]. 


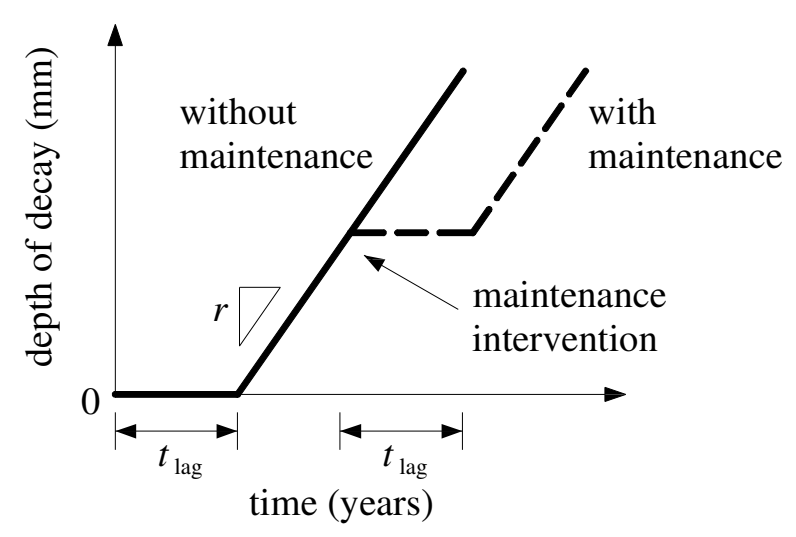

a)

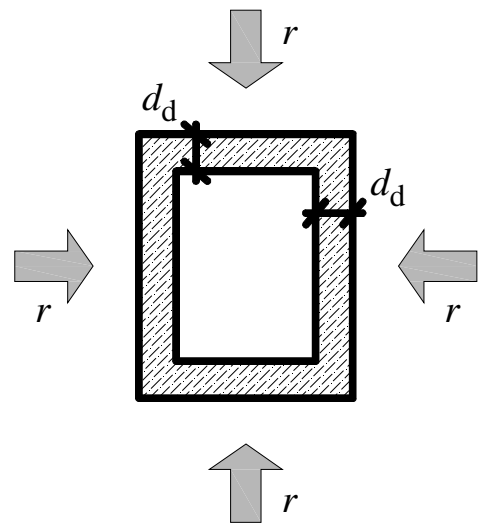

b)

Figure 2 - Decay evolution: a) idealized model, adapted from [53]; b) damage penetration on a decayed cross section, where $d_{\mathrm{d}}$ is the decay depth and $r$ the annual penetration rate, adapted from [29].

\section{ANALYSIS OF SINGLE ELEMENT STRUCTURES}

Next, examples of the use of Bayesian data updating to define a reliability-based assessment of existing timber structures considering the information given by NDT are presented. Individual members of a given timber structure are studied as a single element.

Initially, a reliability assessment is made and compared with the reliability of the structure adopted. The first example consists of a simply supported beam with rectangular cross section, with height $h$ and width $b$. The loads are assumed uniformly distributed along the beam length, $l$. The second example consists of a bottom clamped column with a square cross section (size $a$ ) and length $l_{s}$. The loads are modeled as concentrated loads applied at the top of the column. Both structures are shown in Figure 3 and are composed by elements of solid timber, being the load combination modeled by:

$$
S=(1-\alpha) G+\alpha Q
$$

where $G$ is the permanent load and $Q$ is the variable load (live load in this case), $\alpha$ is a factor between 0 and 1 modeling the fraction of variable load. Aiming to investigate the effect of the variable actions, a similar procedure for load combination is adopted by Honfi et al. [28].

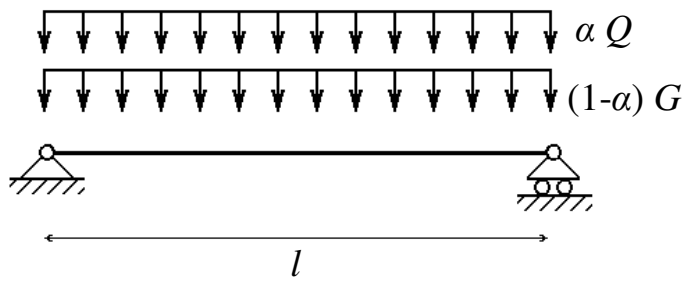

a)

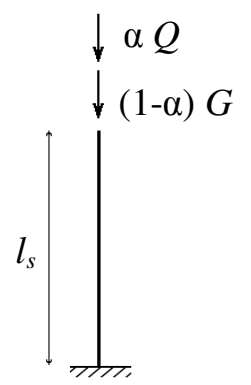

b)

Figure 3 - Structural models: a) simply supported beam; b) bottom clamped column. 
For the reliability verification of structures, limit state equations are required, which in this study were defined with reference to EN 1995-1-1:2004 (Eurocode 5) [44] with the necessary changes for a probabilistic analysis. The modification parameter regarding the effect of load duration and moisture content of timber, $k_{\mathrm{mod}}$, is considered for the load with smaller duration. Reliability based calibration of load duration factors using probabilistic models of loads and short-term and long-term strength is discussed in [57].

After the reliability assessment in design phase, the definition and influence of different climatic zones on decay models and the reliability throughout time are studied. Finally, reliability updating using the resistance drilling test data with different levels of belief and reliability updating using the correlations between NDT and mechanical tests are carried out.

\subsection{Simply supported beam}

In a simply supported beam with uniform loading the limit state equation, as formulated in [23], can be written:

$$
g=\frac{1}{6} b h^{2} k_{\mathrm{mod}} f_{\mathrm{m}}-\frac{1}{8} l^{2}((1-\alpha) G+\alpha Q)
$$

where $f_{\mathrm{m}}$ is the bending strength. The corresponding deterministic design equation, according to the combination of loads in EN 1990:2002 (Eurocode 0) [22], considering the height, $h$, of the cross section as the design parameter, can be written as:

$$
\frac{1}{6} b h^{2} k_{\mathrm{mod}} \frac{f_{\mathrm{m}, \mathrm{k}}}{\gamma_{\mathrm{m}}}-\frac{1}{8} l^{2}\left((1-\alpha) G_{\mathrm{k}} \gamma_{\mathrm{G}}+\alpha Q_{\mathrm{k}} \gamma_{\mathrm{Q}}\right) \geq 0
$$

where $f_{\mathrm{m}, \mathrm{k}}$ is the characteristic bending strength (correspondent to a $5 \%$ percentile), $\gamma_{\mathrm{m}}$ is the partial safety factor for material properties, $G_{\mathrm{k}}$ and $Q_{\mathrm{k}}$ are the characteristic values for permanent and variable loads, corresponding to $95 \%$ and $98 \%$ percentiles, respectively, and $\gamma_{\mathrm{G}}$ and $\gamma_{\mathrm{Q}}$ are the partial safety factors for permanent and variable loads, respectively. Both the material and the load partial safety factors also account for model uncertainties and dimensional variations.

The partial factors used are values that provide an acceptable level of reliability (target reliability) and have been selected assuming that an appropriate level of workmanship and of quality management applies, see [22]. The target reliability values are the result of a calibration process that should lead to a reliability index according to the Probabilistic Model Code (PMC) [49]. The reliability targets are also compatible with observed failure rates and with outcomes of cost-benefit analyses [58]. Present target reliabilities, in many countries, have been found by consideration of the existing codes, aiming that its application should not lead to large differences from those codes. For code calibration, partial factors may be calculated by different approaches, as using the minimum error method or the standardized FORM coefficients (see e.g. [59]). 
The reliability obtained using the design requirements for timber elements subjected to bending from Eurocode 5 [44] is presented in Figure 4. The design parameter $h$ is determined from Eq. (21) for each value of $\alpha$. The obtained reliability level (or index), $\beta$, (with reference period equal to 1 year corresponding to an annual probability of failure) was always above $\beta=4$, reaching values higher than $\beta=4.7$ for $\alpha=0.3$. The mean value in a relevant interval for timber structures $(0.3 \leq \alpha \leq 0.8)$ found for reliability was approximately $\beta=4.5$ (probability of failure, $p_{\mathrm{f}}=3.40 \times 10^{-6}$ ) which is higher than the suggested in the PMC [49] for 1 year reference period and reliability class 1.

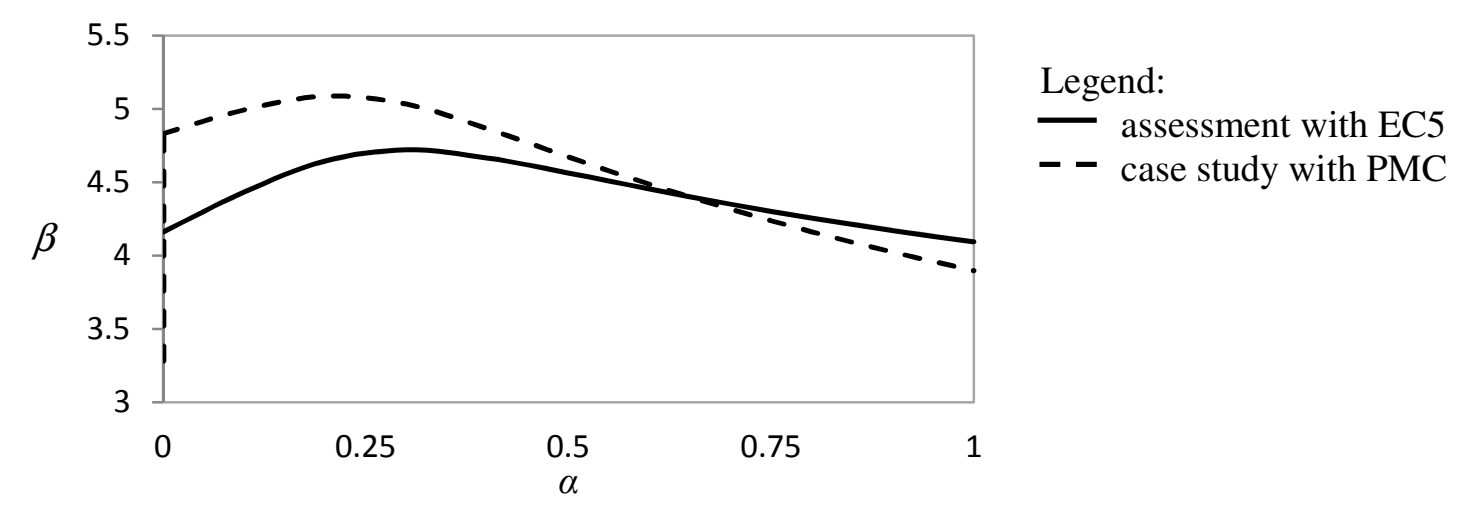

Figure 4 - Reliability index with reference time one year for the simply supported beam with respect to design assessment with Eurocode 5 [44] (continuous line) and assessment of a case study using the Probabilistic Model Code [27] (dashed line).

The results just presented consider the design of any possible element with this configuration. However, when assessing existing structures, it is necessary to use the actual condition and the variables assigned for the stochastic model are given in Table 2. Figure 4 shows again the reliability index for different load combinations (i.e. the design parameter $h=400 \mathrm{~mm}$ is fixed for all values of $\alpha$ ). Different relative fractions of variable and permanent load for an existing structure led to lower or higher values of reliability index compared to initial design assessment. In this case, it can be observed that the reliability index for lower values of $\alpha(0<\alpha \leq 0.60)$ is higher for the existing structure, but for higher values of $\alpha$, the reliability index of the existing structure is lower, which demonstrates the relevance of using a stochastic model for adequate reliability assessment. For the case of $\alpha=0.5$, the resistance and demand distributions curves are presented in Figure 5, where the distance between curves and the small region, when the demand is higher than the resistance, denotes a high reliability. In order to evaluate the differences that climatic factors may have on the reliability level of a structure, an analysis is conducted varying the climatic zones, assuming the models proposed in [54] (climatic zones A to D, being A the less hazardous zone). The decay penetration of each model is dependent on the climatic zone and the durability class of the timber element. For the purpose of this example durability class 1 was considered. The annual reliability indices for the different deterioration curves regarding different climatic zones are presented in Figure 6. A stochastic degradation model presented in [30] is also used, with a lognormal distributed $r$ with mean equal to $0.075 \mathrm{~mm} / \mathrm{year}$ and COV of 
0.70, which was chosen as representative of the decay agents found in Southwestern Europe and local wood species. For illustrative purposes, a load coefficient $\alpha=0.5$ is considered in all models.

Table 2 - Variables used in the stochastic model for a simply supported beam [27].

\begin{tabular}{cccccc}
\hline Variable $[\boldsymbol{X}]$ & Distribution & $\boldsymbol{E}[\boldsymbol{X}]$ & $\boldsymbol{C O V}[\boldsymbol{X}]$ & Description & Characteristic values Eq. (21) \\
\hline$f_{\mathrm{m}}$ & Lognormal & $25 \mathrm{~N} / \mathrm{mm}^{2}$ & 0.25 & Bending strength & $5 \%$ \\
$G$ & Normal & $6 \mathrm{~N} / \mathrm{mm}$ & 0.10 & Permanent load & $95 \%$ \\
$Q$ & Gumbel & $4 \mathrm{~N} / \mathrm{mm}$ & 0.40 & Annual maximum live load & $98 \%$ \\
$h$ & Deterministic & $400 \mathrm{~mm}$ & - & Height of the cross section & - \\
$b$ & Deterministic & $200 \mathrm{~mm}$ & - & Width of the cross section & - \\
$l$ & Deterministic & $6600 \mathrm{~mm}$ & - & Length of the beam & -
\end{tabular}

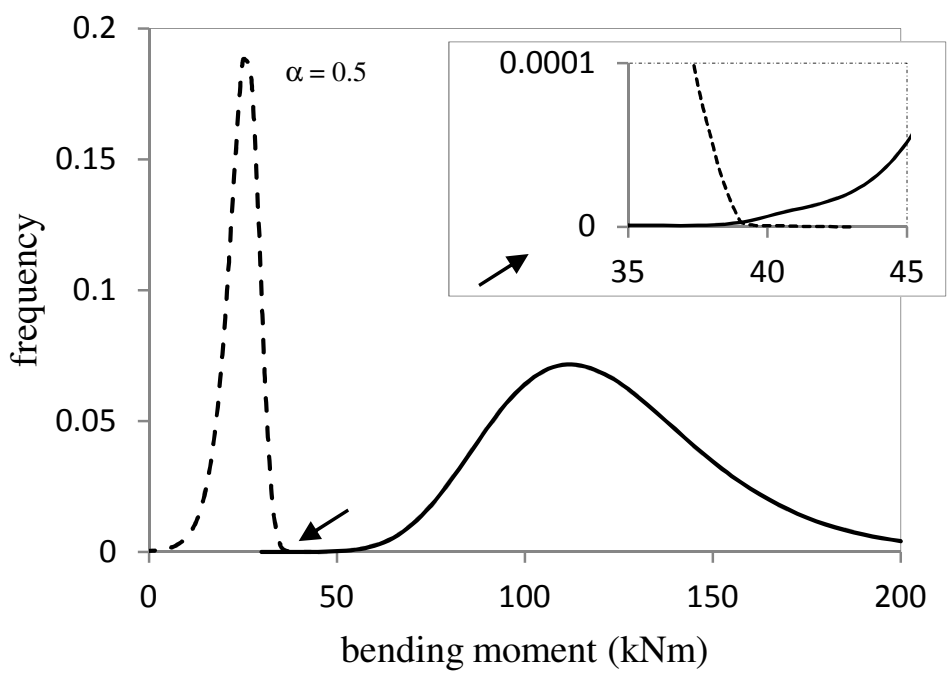

Legend:

- resistance distribution

- - demand distribution

Figure 5 - Resistance and demand distribution for the simply supported beam for the case study using the Probabilistic Model Code [27].

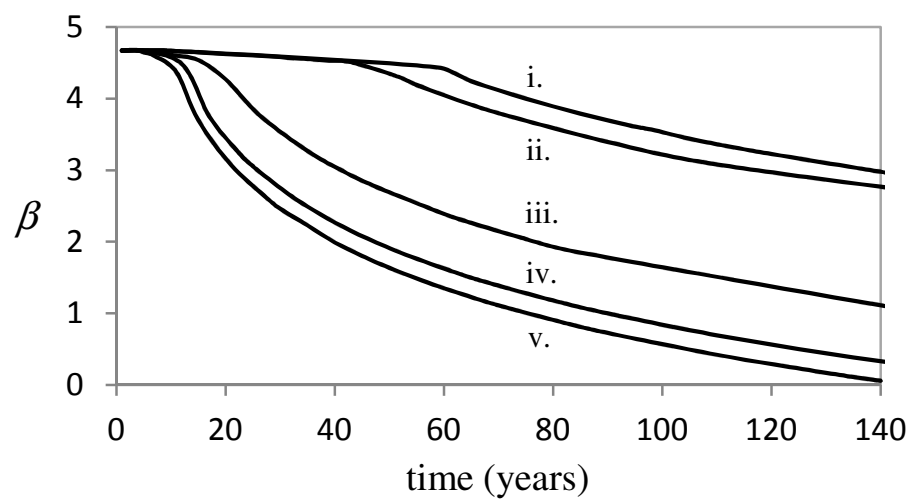

Legend (from top to bottom):

i. model adapted from [30]

ii. climatic zone A $(r=0.08$ $\mathrm{mm} /$ year)

iii. climatic zone $\mathrm{B} \quad(r=0.25$ $\mathrm{mm} /$ year)

iv. climatic zone $\mathrm{C} \quad(r=0.41$ $\mathrm{mm} / \mathrm{year}$ )

v. climatic zone $\mathrm{D} \quad(r=0.50$ $\mathrm{mm} /$ year)

Figure 6 - Reliability indices evolution through time using deterioration models $[30,56]$ for different climatic zones. 
The results evidence that the annual reliability index decreases faster when the climatic conditions are more hazardous, as the propagation of deterioration in the timber element is also faster. When comparing the different models, it is seen that the higher reliability curve is given by the stochastic model presented in [30] with $r=0.075 \mathrm{~mm} /$ year, since it presents the lower penetration rate. The results of choosing different deterioration models, in terms of resistance cumulative distributions, are presented in Figure 7, for a time equal to 50 years. These distributions evidence lower values of resistance for the models which led to lower reliability levels, as the deterioration process is considered more severe for these models.

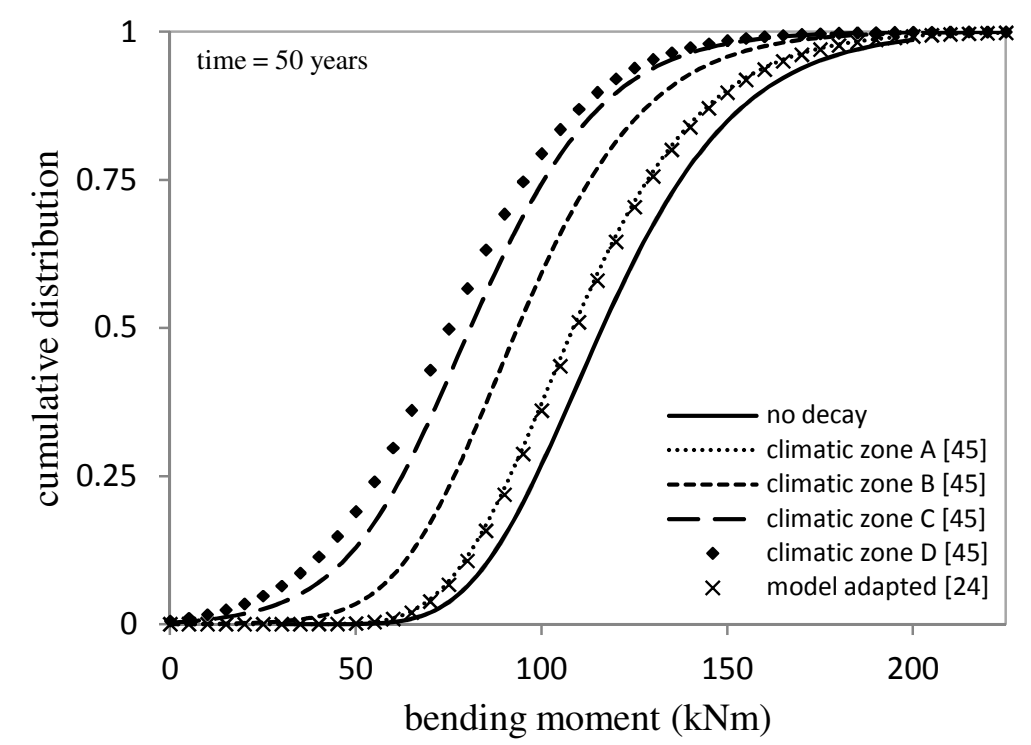

Figure 7 - Example of the resistance distribution functions for the decay models in the simply supported beam, after 50 years.

Failure rates, $\lambda$, indicate the number of failures in correspondence to the time before failure, thus may be taken as the frequency of failure. Failure rates (by annual probabilities of failure) evolution through time was calculated using the degradation model from [30] and the model proposed in [54] with climatic zone D. These models correspond to the extreme cases in the reliability analysis. Figure 8 shows that the value of the failure rate maintains almost constant for the period of time where a low decrease in the reliability level is present, followed by a steep increase after that period. As expected, failure rates are significantly higher when considering models with higher decay influence.

The reliability values obtained in the first assessment assuming the evolution in time due to decay activity can be updated with relevant data gathered regarding in situ inspection by NDT. To illustrate the advantages of using the updating scheme an example of resistance drilling tests is used. These tests allow determining areas with different resistance to drilling, thus enabling the detection of decayed areas and the residual cross section. Assuming the loss of resistance as a consequence of decay, and defining the time of exposure, it is possible to obtain the penetration rate $r$ with respect to the resistant area detected by resistance drilling measurements. Therefore, for each measurement of the NDT 
indicator it is possible to derive the residual cross section and to update the deterioration model with respect to the $r$ parameter.

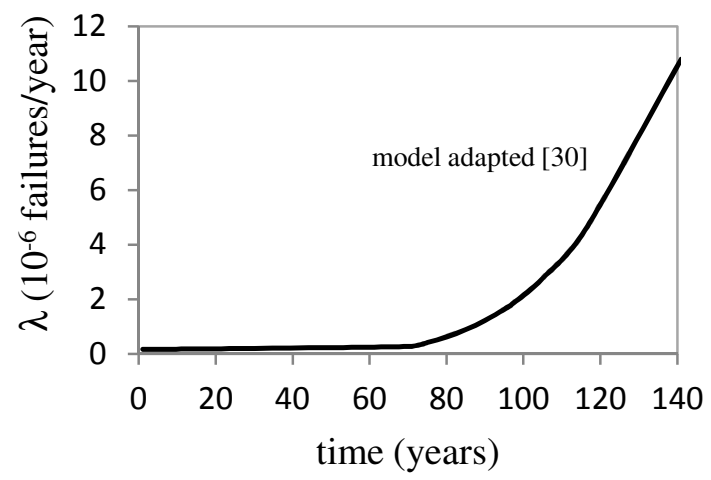

a)

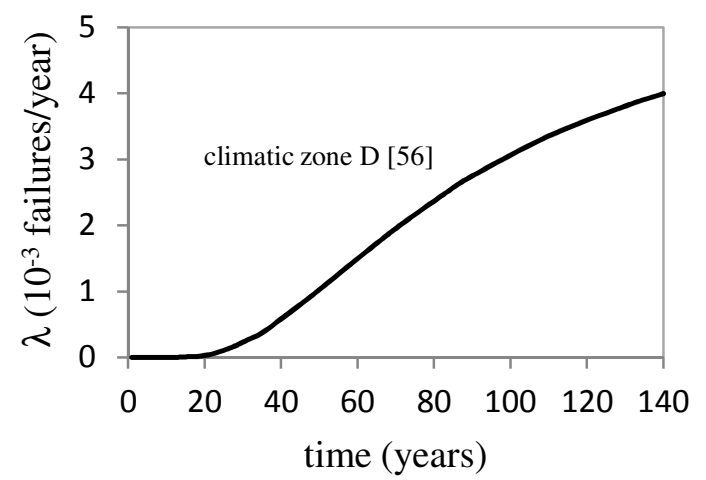

b)

Figure 8 - Failure rates (by annual probabilities of failure) evolution through time according to deterioration models: a) adapted from [30]; b) adapted from [56] with climatic zone D.

The resistance drilling tests performed on the structure are assumed to be performed in year 20. For illustrative purposes, the model that led to lower reliability in Figure 6 was considered and eight tests were performed obtaining different values of residual cross section $(n=$ number of tests; $m=$ sample mean; $s=$ sample standard deviation), see Table 3. With respect to the degree of belief in the updating data, two possibilities for prior information are considered: a) vague prior information on the mean value and standard deviation equal to 0.35 and, $b$ ) vague prior information on mean value and standard deviation. For vague information on mean value and standard deviation, the prior information parameters are such that:

- hypothetical sample average, $m^{\prime}$, and sample standard deviation, $s^{\prime}$, are not relevant;

- $\quad$ hypothetical number of observations for $m^{\prime}, n^{\prime}=0$;

- hypothetical number of degrees of freedom for $s^{\prime}, v^{\prime}=0$.

Table 3 - Sample of penetration rates derived from resistance drilling tests (eight cross section measurements are assumed).

\begin{tabular}{|c|c|c|c|c|c|c|c|c|c|c|}
\hline & & & & $r(\mathbf{m n}$ & /year) & & & & $m$ & $s$ \\
\hline$r_{i}$ & 0.45 & 0.52 & 0.65 & 0.47 & 0.40 & 0.42 & 0.55 & 0.54 & 0.50 & 0.082 \\
\hline$Y_{i}=\ln \left(r_{i}\right)$ & -0.799 & -0.654 & -0.431 & -0.755 & -0.916 & -0.868 & -0.598 & -0.616 & -0.70 & 0.160 \\
\hline
\end{tabular}

Thus, the posterior parameters become: $\quad n^{\prime \prime}=n=8 ; \quad v^{\prime \prime}=n-1=7 ; \quad m^{\prime \prime}=m=-0.70 \quad$ and $\left(s^{\prime \prime}\right)^{2}=s^{2}=0.0256$. The predictive value of $r$, as formulated in e.g [47], is given by:

$$
r_{\mathrm{d}}=\exp (m(Y)) \cdot \exp \left(-t_{\mathrm{vd}} \cdot s(Y) \cdot \sqrt{1+\frac{1}{n}}\right)
$$

where $t_{v \mathrm{~d}}$ has a central t-distribution. 
As an example, for the $95 \%$ quantile, $t_{v d}=-1.895$ and the predictive value for $r_{\mathrm{d}}=0.68 \mathrm{~mm} / \mathrm{year}$ is obtained with a standard deviation of $0.16 \mathrm{~mm} / \mathrm{year}$.

For the second approach, it is assumed that the information from the standard deviation of $r$ is known to be equal to $0.35 \mathrm{~mm} /$ year. The prior information parameters become: $m^{\prime}$ is not relevant; $s^{\prime}=0.35$; $n^{\prime}=0 ; v^{\prime}=\infty$ and the posterior parameters become: $n^{\prime \prime}=n=8 ; v^{\prime \prime}=\infty ; m^{\prime \prime}=m=-0.70$ and $\left(s^{\prime \prime}\right)^{2}=s^{2}=0.12$. With respect to Eq. (22) and assuming $t_{v \mathrm{~d}}=t_{\infty}=-1.645$ for the $95 \%$ quantile, a predictive value for $r=0.91 \mathrm{~mm} /$ year is obtained with associated standard deviation of $0.35 \mathrm{~mm} /$ year. The influence of the updating process in the resistance distribution is presented in Figure 9, for time of 20 years (date of inspection) and at time equal to 50 years. In this case, the model updated with prior information presents closer reliability levels compared to the model with no updating, as the lower tail of the distributions are similar. The difference between resistance distributions for different time periods is therefore evidenced. In the case of time equal to 50 years, the lower variation for model after updating compared to the model with no update is clear.

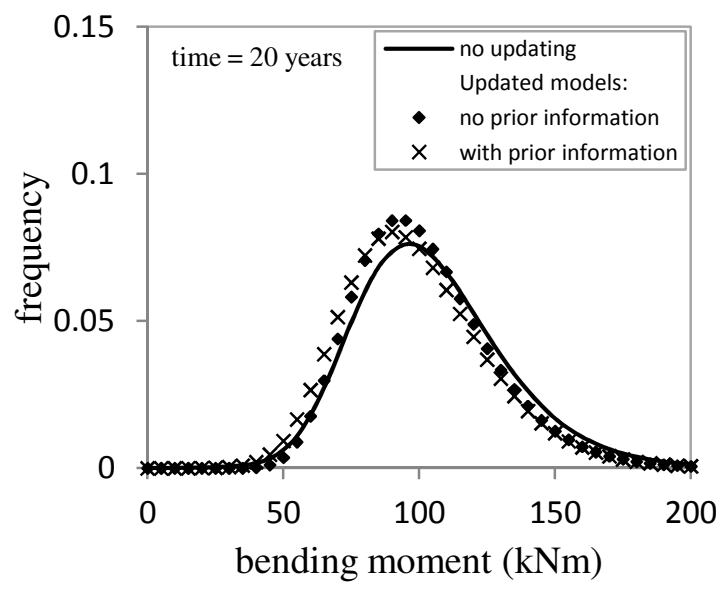

a)

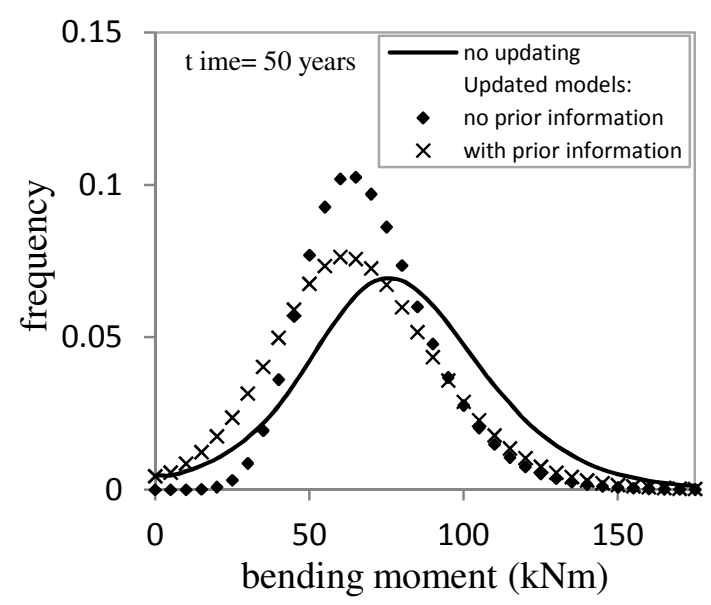

b)

Figure 9 - Resistance distributions for the simply supported beam before and after updating, according to decay evolution: a) at 20 years (year of inspection); b) at 50 years.

The values for the updated stochastic model using the new information are implemented in the deterioration model, and the updated reliability is estimated again. Figure 10 shows the updated annual reliability indices. By calculating the probability of failure, $p_{\mathrm{f}}$, and the corresponding reliability index, $\beta$, decisions on inspections and repairs can be initiated when the reliability index reaches a given critical threshold. Once a temporal record of $\beta$ has been established it is also possible to calculate the time when a particular value of $\beta$ is reached [51]. 


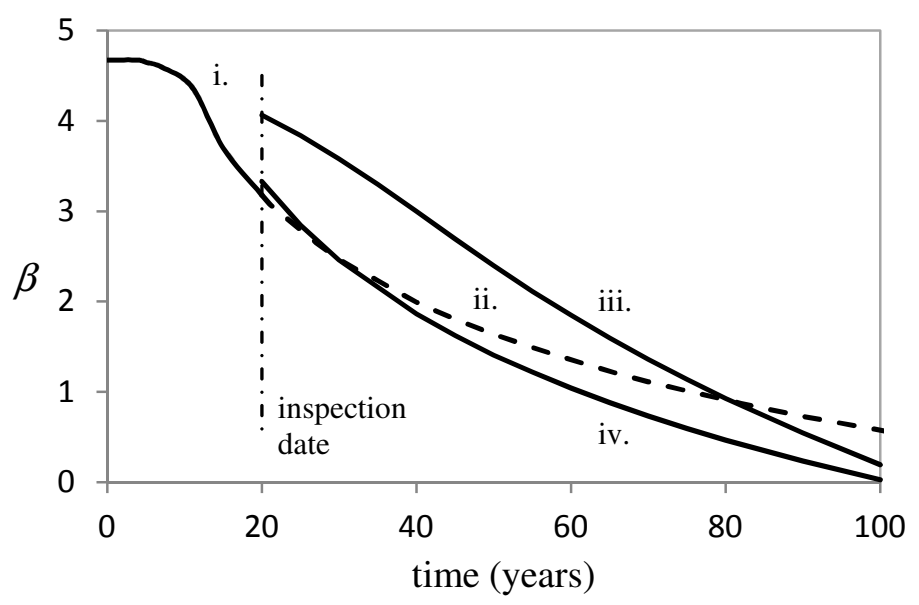

Legend: Decay models:

i. assumed before NDT information

ii. after NDT information, without updating

iii. updated model with NDT data, with no prior information

iv. updated model with NDT data with $\sigma$ known

Figure 10 - Reliability indices evolution through time with updating, using deterioration model in [56].

By updating the model with NDT data with uncertain information about the mean and standard deviation, an increase in the structural safety reliability values is visible compared to the expected by the decay model prediction. The differences, although significant, may be explained by different reasons in real life, as the element may have not been exposed to extreme conditions of humidity or temperature or it might be from a higher durability class than originally assumed in the decay model. However, since a significant difference between reliability values was found, and in this case may provide unsafe reliability assessments, it is necessary to confirm the accuracy of the data with more information. From Figure 10 and between the two updated models, it is seen that with the model updated with $\sigma$ known, it is possible to find lower values of the reliability index. The reason is that the $\mathrm{COV}$ in the prior information is higher than the one observed using the NDT results. From these results, two conclusions can be made: (i) in the case with vague information on the mean and standard deviation, either the information is not adequate to this specific structure and climate and, thus should be disregarded; (ii) or, the number of tests is insufficient and therefore the observation sample is not adequate and should be improved with information about the standard deviation.

It is noted that results given by NDT may provide either an increase or decrease in structural safety reliability compared to the predictive models. Therefore, it is erroneous to conclude that updating a model leads to a better or worse level of safety reliability. In reality, it can only be stated that updating a model will only provide a more accurate and precise definition of the structural behavior of a specific element or system of elements in terms of reliability.

\subsection{Column}

In a perfect column, the limit state equation is related to the maximum compressive stress along the height of the column given, as formulated in [23], by: 


$$
g=k_{\mathrm{mod}} f_{\mathrm{c}, 0}-((1-\alpha) G+\alpha Q) / A
$$

where the compressive strength parallel to the grain is $f_{\mathrm{c}, 0}$.

Considering the area of the cross section, $A$, as the design parameter, the design equation, according to the combination of loads in [22], can be written as:

$$
k_{\mathrm{mod}} \frac{f_{\mathrm{c}, 0, \mathrm{k}}}{\gamma_{\mathrm{m}}}-\left((1-\alpha) G_{\mathrm{k}} \gamma_{\mathrm{G}}+\alpha Q_{\mathrm{k}} \gamma_{\mathrm{Q}}\right) / A \geq 0
$$

Based on a semi-deterministic approach using partial safety factors, the load variables are defined through their characteristic values, and the remaining parameters are deterministic. The reliability index obtained by the design of timber elements subjected to pure compression, from Eurocode 5 [44], is presented in Figure 11 for each value of the fraction of variable load $\alpha$. For this analysis the cross section area, $A$, of the column should be such that buckling is disregarded (slenderness ratio $\lambda_{\text {rel }} \leq 0.3$ [44]).

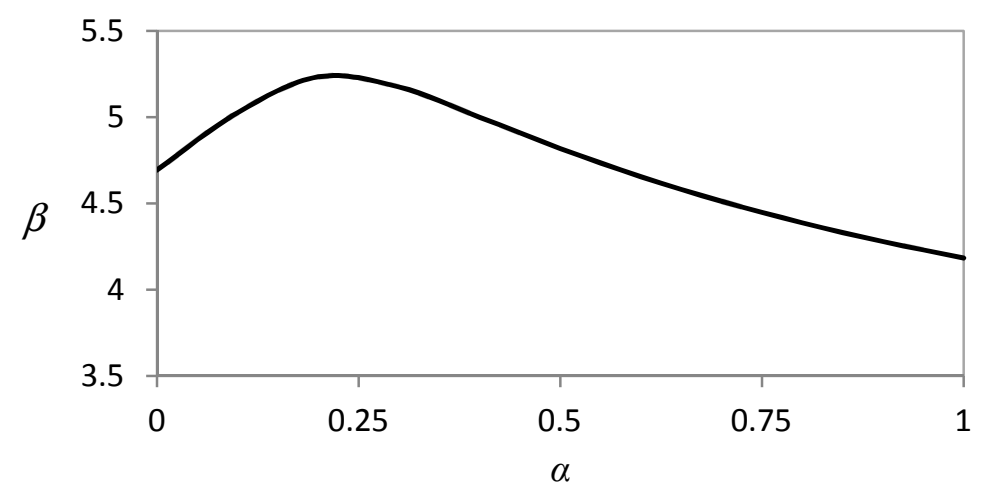

Figure 11 - Annual reliability index with reference time one year for the column element with respect to Eq. (24).

The obtained mean reliability index is approximately $\beta=4.7\left(p_{\mathrm{f}}=1.30 \times 10^{-6}\right)$ which is higher than the suggested by [49] for 1 year reference period and reliability class $1(\beta=4.2)$ but equal to the required in Eurocode 0 annex B [22] for reliability class RC2. Also, it is noticeable that this limit state equation for pure compression produces reliabilities with dependence of $\alpha$ similar to the simple bending limit state equation, see (Figures 4 and 11). However, the reliability values obtained using the limit state equations suggested by Eurocode 5 [44] for design in pure compression are higher than for simple bending. Another difference is that, in this case, $\beta$ for $\alpha=1$ is much smaller than $\beta$ for $\alpha=0$.

In order to have a practical updating example, a cross section of $60 \times 60 \mathrm{~mm}^{2}$ is considered for analysis. The objective of this updating analysis is to have a suitable method to update the value of compressive strength parallel to the grain $\left(f_{\mathrm{c}, 0}\right)$ of a timber elements when NDT results are available and also to consider the uncertainty involved in this process. 
Next a reliability analysis is conducted for evaluation of the validity of the considered correlations. Also this procedure aims at analyzing the influence of the uncertainty introduced by each separate NDT. Firstly, the resistance parameters of the column are implemented in the reference stochastic models considering the values for $f_{\mathrm{c}, 0}$ given by the destructive tests (DT). Then, for an updating scheme, $f_{\mathrm{c}, 0}$ is determined with respect to the linear regression model obtained by the Maximum Likelihood method for each NDT. The parameters of the models are given in Table 4. The two reference models for $f_{\mathrm{c}, 0}$ pretend to establish a benchmark for comparison. In the first model, the average value of $f_{\mathrm{c}, 0}$ is chosen equal to the sample average of DT with COV as proposed in [27]. In the second model, $f_{\mathrm{c}, 0}$ is modeled by the sample average and COV as obtained in the DT. For both models, a lognormal distribution is assumed.

Table 4 - Variables used in the stochastic model for a column example.

\begin{tabular}{|c|c|c|c|c|}
\hline Variable $[X]$ & Distribution & $E[X]$ & $\operatorname{COV}[X]$ & Description \\
\hline$f_{\mathrm{c}, \mathrm{o}}$ & Lognormal & $\mu_{\mathrm{DT}}$ & 0.2 & $\begin{array}{c}f_{\mathrm{c}, 0}-\text { average value of destructive tests (reference } \\
\text { model) }\end{array}$ \\
\hline$f_{\mathrm{c}, \mathrm{o}}$ & Lognormal & $\mu_{\mathrm{DT}}$ & $\sigma_{\mathrm{DT}}=0.15$ & $\begin{array}{c}f_{\mathrm{c}, 0}-\text { average value and COV of destructive tests } \\
\text { (reference model) }\end{array}$ \\
\hline$f_{\mathrm{c}, \mathrm{o}}$ & - & $\mathrm{a}_{0}+\mathrm{a}_{1} \cdot \mu_{\mathrm{RM}}+\varepsilon$ & - & $f_{\mathrm{c}, 0}-$ average value of resistance drilling tests \\
\hline$f_{\mathrm{c}, \mathrm{o}}$ & - & $\mathrm{a}_{0}+\mathrm{a}_{1} \cdot \mu_{\text {depth }}+\varepsilon$ & - & $f_{\mathrm{c}, 0}-$ average value of pin penetration tests \\
\hline$f_{\mathrm{c}, \mathrm{o}}$ & - & $\mathrm{a}_{0}+\mathrm{a}_{1} \cdot \mu_{\mathrm{Edyn}}+\varepsilon$ & - & $f_{\mathrm{c}, 0}-$ average value of ultrasound tests \\
\hline$\varepsilon$ & Normal & 0 & $\sigma_{\varepsilon}$ & Uncertainty parameter of each NDT \\
\hline G & Normal & $60000 \mathrm{~N}$ & 0.10 & Permanent load \\
\hline$Q$ & Gumbel & $40000 \mathrm{~N}$ & 0.40 & Annual maximum live load \\
\hline$A$ & Deterministic & $3600 \mathrm{~mm}^{2}$ & - & Area of the cross section \\
\hline
\end{tabular}

According to the considered NDT data, three models are used with respect to each type of test. The results for the reference models and for the models updated by the correlations between $f_{\mathrm{c}, 0}$ and results from NDT are given in Figure 12. The results show higher values of reliability index for the models updated with NDT data. This is mainly due to the consideration of the correlation between DT and NDT used to update $f_{\mathrm{c}, 0}$. Although uncertainty is implemented through consideration of parameter $\varepsilon$, the variation of $f_{\mathrm{c}, 0}$ is lower than when the coefficient of variation of the reference models is used.

The resistance drilling and ultrasound updating schemes, which presented similar results, must be used with attention since they led to higher values of reliability than the references values. The updating scheme regarding the data from the pin penetration tests gave lower values of reliability. The main differences are found for the maximum value of the reliability curves around from $\alpha=0$ to $\alpha=0.25$. However, the data with respect to the pin penetration tests presented more approximated values to one of the reference models. 


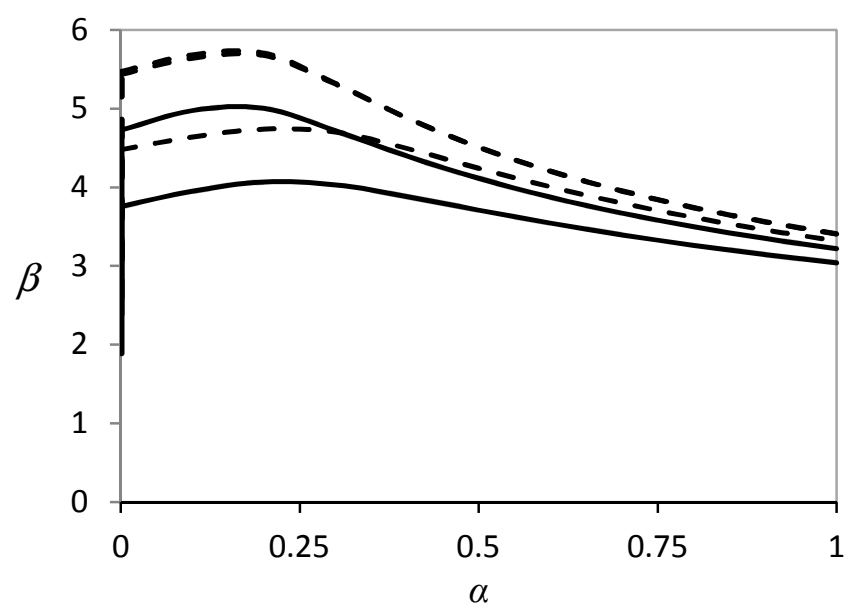

Legend (from top to bottom, in $\alpha=0$ ):

Continuous line: reference models

$$
\begin{aligned}
& f_{\mathrm{c}, 0}=\mu_{\mathrm{DT}} ; \mathrm{COV}_{\mathrm{DT}}=0.15\left(\beta_{\alpha=0}=2.39\right) \\
& f_{\mathrm{c}, 0}=\mu_{\mathrm{DT}} ; \mathrm{COV}=0.20 \quad\left(\beta_{\alpha=0}=1.89\right)
\end{aligned}
$$

Dashed line: models with NDT information

$$
\begin{array}{ll}
f_{\mathrm{c}, 0}=\mathrm{a}-\mathrm{b} \cdot \mu_{\mathrm{Edin}}+\varepsilon & \left(\beta_{\alpha=0}=3.08\right) \\
f_{\mathrm{c}, 0}=\mathrm{a}-\mathrm{b} \cdot \mu_{\mathrm{RM}}+\varepsilon & \left(\beta_{\alpha=0}=3.08\right) \\
f_{\mathrm{c}, 0}=\mathrm{a}-\mathrm{b} \cdot \mu_{\text {depth }}+\varepsilon & \left(\beta_{\alpha=0}=2.60\right)
\end{array}
$$

Figure 12 - Annual reliability index of reference models and updated models obtained by NDT data.

Figure 13 presents the demand distribution and the resistance distributions for the reference models and models after updating by NDT data, for $\alpha=0.5$. The lower variation in the models after updating is visible with also higher expected values. As also indicated in the previously analysis, the pin penetration test data led to values closer to the reference models.

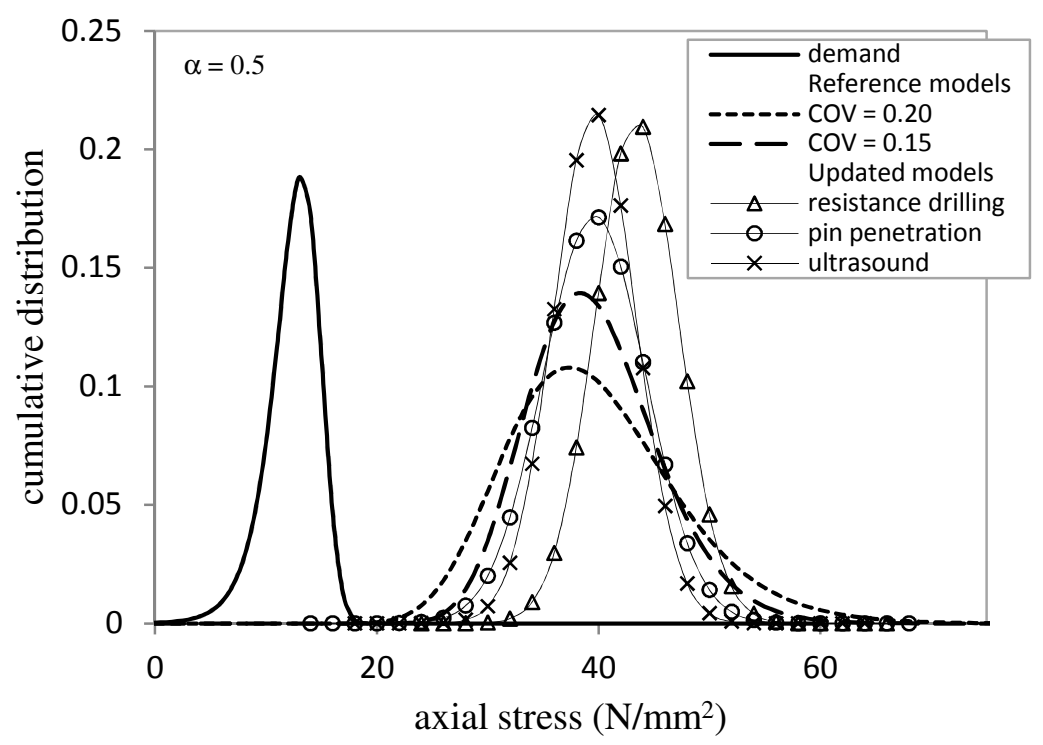

Figure 13 - Resistance and demand distributions for the column for reference models (no updated) and models updated by NDT.

\section{APPLICATION TO A TRUSS STRUCTURE}

Finally, an illustrative example of a planar timber truss is considered (Figure 14), submitted to permanent, $G$, and live load, $Q$. Considering that the elements of this kind of structures are mainly subjected to axial stresses, three different limit state conditions are initially assumed. The limit state 
equations are related to tension and compression parallel to grain, and to instability due to buckling of compressed elements.

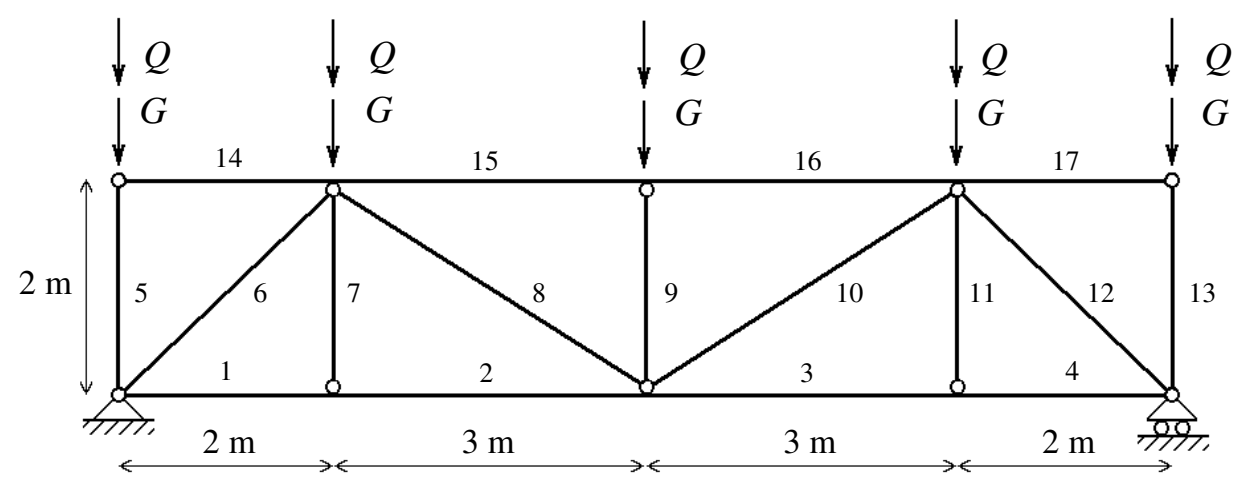

Figure 14 - Structural model of a planar timber truss.

\subsection{Design}

Before conducting any reliability assessment, the different elements must be designed in terms of cross section dimensions. The structure is assumed to be constructed with chestnut wood, however with consideration, in the design procedure, of two different strength classes. The classes considered are D30 and D50 as given in [45]. For both cases, the structural design respected the following usual hypotheses: tensile elements $(1,2,3,4,8,10)$ have $75 \%$ of the cross section used; compressive elements $(5,6,9,12,13,15,16)$ have $95 \%$ of the cross section used, with respect to buckling verification; the cross sections are uniform in order to allow an easier construction process; the vertical elements $(5,7,9,11,13)$ all have the same dimension, determined by the most stressed element (9); the chords are composed by single $10 \mathrm{~m}$ long elements.

These hypotheses provide that the most critical limit states are related to compression parallel to the grain, allowing the use of the previous NDT correlations as updating data. Taking into account that two different strength classes of timber were considered, for each design, different cross sections were obtained for the truss members. In the following description, each structure will be defined by D30 or D50 design, according to the used timber strength class.

In this example, failure of the lower or upper chords would correspond to the structural failure of the system, which is a series type behavior in reliability analysis. Therefore, the chords represent key elements of the structure.

\subsection{Reliability analysis}

For the D30 design, the reliability index of the structure (reference period time of one year) for a series system is found to be $\beta=5.18$ ( $p_{\mathrm{f}}=1.11 \times 10^{-7}$ ) (failure of the upper chord by instability), whereas for the D50 design the annual reliability index of the structural system is found to be $\beta=4.64$ $\left(p_{\mathrm{f}}=1.74 \times 10^{-6}\right)$ (failure of the upper chord by instability). In [3] typical failures patterns evidenced the 
presence of buckling fibers due to splitting almost parallel to the grain. Similar behavior was found in [30], when studying the reliability of decayed timber trusses, with buckling due to the large slenderness of deteriorated elements.

Although the reliability indices in D30 design for elements 6, 8, 10 and 12 are lower than the reliability indices of element 15 and 16, the failure of these elements does not correspond to a structural failure, whereas failure of one element of the upper chord leads to a global failure. As referred by Vrouwenvelder [60], although the reliability targets refer to the structural system as a whole, in most cases, probabilistic design is performed at the member level. Therefore, the system failure is ruled by that particular member.

The design using D50 timber produces lower values of reliability indices due to the assumed design considerations that defined different cross sections for each design. The reliability indices for each element regarding both designs are shown in Table 5.

Table 5 - Reliability indices for each element of the truss structure with probability of failure in brackets (period reference one year).

\begin{tabular}{|c|c|c|c|c|c|c|c|c|c|}
\hline \multirow[b]{2}{*}{ Design } & \multicolumn{9}{|c|}{ Elements } \\
\hline & 1,4 & 2,3 & 5,13 & 6,12 & $\begin{array}{l}\text { 7, } \\
11\end{array}$ & 8,10 & 9 & $\begin{array}{l}14, \\
17\end{array}$ & 15,16 \\
\hline D30 & $\begin{array}{c}5.22 \\
\left(8.95 \times 10^{-8}\right)\end{array}$ & $\begin{array}{c}5.22 \\
\left(8.95 \times 10^{-8}\right)\end{array}$ & $\begin{array}{c}10.39 \\
\left(<1 \times 10^{-15}\right)\end{array}$ & $\begin{array}{c}5.08 \\
\left(1.89 \times 10^{-7}\right)\end{array}$ & $*$ & $\begin{array}{c}5.01 \\
\left(2.72 \times 10^{-7}\right)\end{array}$ & $\begin{array}{c}5.44 \\
\left(2.66 \times 10^{-8}\right)\end{array}$ & $*$ & $\begin{array}{c}5.18 \\
\left(1.11 \times 10^{-7}\right)\end{array}$ \\
\hline D50 & $\begin{array}{c}4.95 \\
\left(3.71 \times 10^{-7}\right)\end{array}$ & $\begin{array}{c}4.95 \\
\left(3.71 \times 10^{-7}\right)\end{array}$ & $\begin{array}{c}9.40 \\
\left(<1 \times 10^{-15}\right)\end{array}$ & $\begin{array}{c}4.55 \\
\left(2.68 \times 10^{-6}\right)\end{array}$ & $*$ & $\begin{array}{c}5.10 \\
\left(1.70 \times 10^{-7}\right)\end{array}$ & $\begin{array}{c}4.88 \\
\left(5.30 \times 10^{-7}\right)\end{array}$ & $*$ & $\begin{array}{c}4.64 \\
\left(1.74 \times 10^{-6}\right)\end{array}$ \\
\hline
\end{tabular}

As mentioned by Moore et al. [51], in presence of degradation processes, the lifetime of components can be severely reduced. Therefore, after the evaluation of the safety level in initial condition (design stage or present stage), also the consideration of deterioration of members was considered in the evolution of reliability along time. However, when considering deterioration in a reliability analysis of a structure composed by a system of different elements, the key elements must be found first. In order to identify the key elements and the most critical limit state regarding deterioration of the timber elements, a reliability assessment was performed considering a perimetral loss of cross section, $\tau$, for each element separately. The elements considered as key elements are those for which the influence of perimetral loss of cross section would be more pronounced corresponding to lower reliability indices. A similar procedure is presented by Moore et al. [51] in assessing the probability that a structural timber element will exceed a specific limit state as the effective cross section diameter decreases.

The key elements for each limit state are shown in Figure 15. The initial values $(\tau=0)$ for the most critical limit states are in accordance to usual design values. For D30, the reliability index of the key elements is $\beta=5.01\left(p_{\mathrm{f}}=2.72 \times 10^{-7}\right)$, whereas for D50 the reliability index is $\beta=4.88\left(p_{\mathrm{f}}=5.30 \times 10^{-7}\right)$. For the structure with D30 timber, tension parallel to grain is the most critical limit state at the beginning of loss of cross section in elements 8 and 10. However, when the reliability index values 
start to be smaller than $4.5\left(p_{\mathrm{f}}=3.40 \times 10^{-6}\right)$, the most critical limit state condition is given by buckling in element 9. For D50 timber, the buckling limit state is always the most critical with element 9 as a key element. Since timber tensile behavior is more influenced by the presence of defects than compression, tension strength parallel to grain is more sensitive to the strength class than compression strength parallel to grain. Element 9 is also considered as a key element because when weakened, or in case of failure, the stresses are redistributed to the other elements of the truss producing shear and bending stresses in the upper chord. Since the upper chord was not initially designed for that kind of stress, its reliability highly decreases and structural failure is a likely scenario. The increase of shear and bending stresses in the upper chord is mainly noticeable when elements 8,9 or 10 are weakened.

Regarding the influence of a decay process in element 9, the structural reliability index (corresponding to the failure of a parallel system with first failure in the decayed element) would be $\beta=6.28$ $\left(p_{\mathrm{f}}=1.69 \times 10^{-10}\right)$ and $\beta=5.90\left(p_{\mathrm{f}}=1.82 \times 10^{-9}\right)$ for D30 and D50 design, respectively. In D30 design, failure of element 9 by instability would be followed by the failure of the upper chord by shear. In D50 design, the failure of element 9 by instability would be followed by failure of the upper chord by lateral torsional instability.

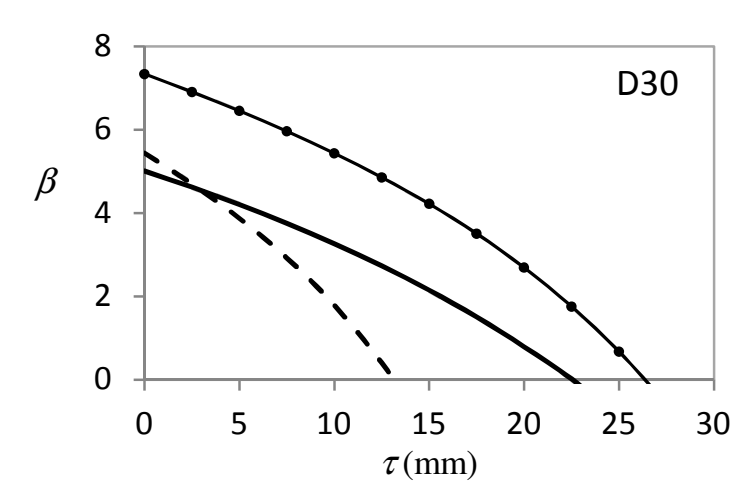

Legend:

- - buckling (element 9)

- tension (elements 8 and 10)

$\rightarrow$ compression (element 9)

a)

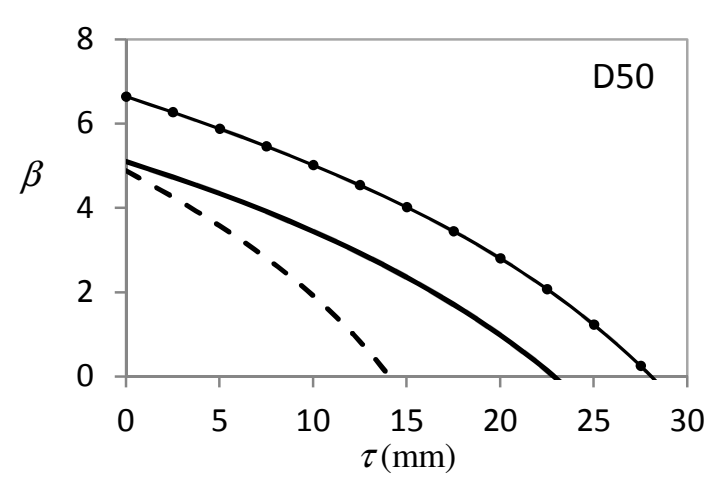

Legend:

- - buckling (element 9)

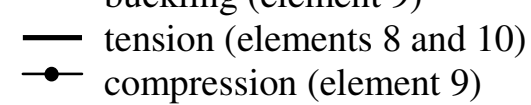

b)

Figure 15 - Annual reliability index with respect to perimetral loss of cross section for the limit state conditions: buckling (element 9) - dashed line; tension (elements 8 and 10) continuous line; compression (element 9) - dotted line, in a) D30 design; b) D50 design.

For illustration of the applicability of an updating process regarding NDT information and its use in the assessment of evolution in time of performance regarding the key elements of an existing timber structure, the data obtained by the Maximum Likelihood estimates given in Table 1 are considered as example data to update the reliability of the truss system. In this case, the NDT data does not intend to replace the strength grading provided by EN 338:2009 [45], but to be considered as possible new information given by an in-situ evaluation. Therefore, the cross section geometry is taken from the design procedures, however $f_{\mathrm{c}, 0}$ is updated by the NDT information. For illustration purposes, the truss 
designed with D50 chestnut timber was analyzed considering the information given by the pin penetration tests. D50 design was considered because the data from the NDT in Feio et al. [39] correspond to results obtained from small clear specimens that are better compared to higher strength grading classes, where lower percentages of defects are admissible. The data from the pin penetration tests was considered due to its better fit found in the assessment of the single column element (see Figure 12) when compared to one of the reference models that considered the data from the DT. In order to analyze the safety reliability assessment and updating process, the demand and resistance distributions curves are exemplified for element 9 according to the most conditioning limit state in this case (instability by buckling) (Figure 16). To that aim, resistance curves consider the D50 design without updating and the results of the updating process with the pin penetration tests are considered. In this case, the updating process led to higher values of resistance with lower variation, and therefore an increase in the safety reliability level.

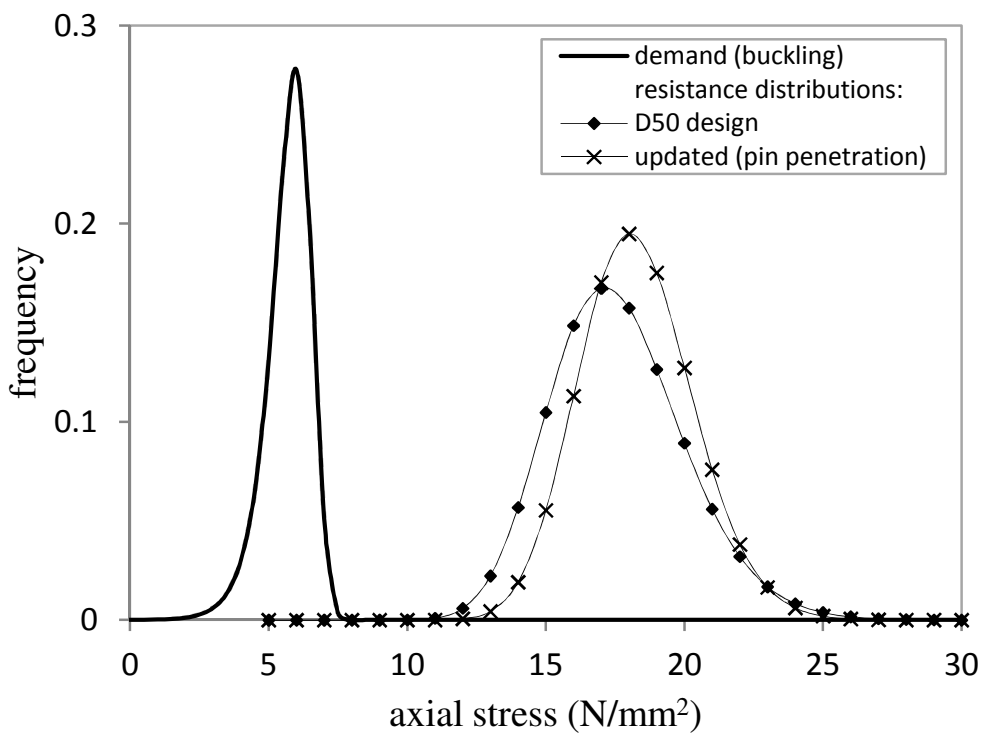

Figure 16 - Resistance and demand distributions (buckling limit state) for element 9 of the truss for D50 design and model updated by pin penetration test data.

After updating the resistance parameters, a deterioration process was considered for elements 9 and 15 separately. Then, the reliability of the structural system was calculated (Figure 17). A parallel system model was used with the necessary failures of elements for a global collapse. Load redistribution to other elements was accounted during the deterioration process of the elements 9 and 15 . Since no information is known for the environmental conditions, the loss of cross section was not assumed time dependent. With this definition, the structural reliability is directly related to a deterioration measure: the cross section loss parameter, $\tau$. When new information is obtained by NDT on the rate of deterioration (e.g. as seen for the simply supported beam example updated by resistance drilling test data), the loss of cross section may be related to the penetration rate, $r$. After gathering the information about the penetration rate, a model of deterioration may be implemented and correlated with the 
corresponding reliability, which will finally lead to a time evolution curve for reliability assessment of the structure.

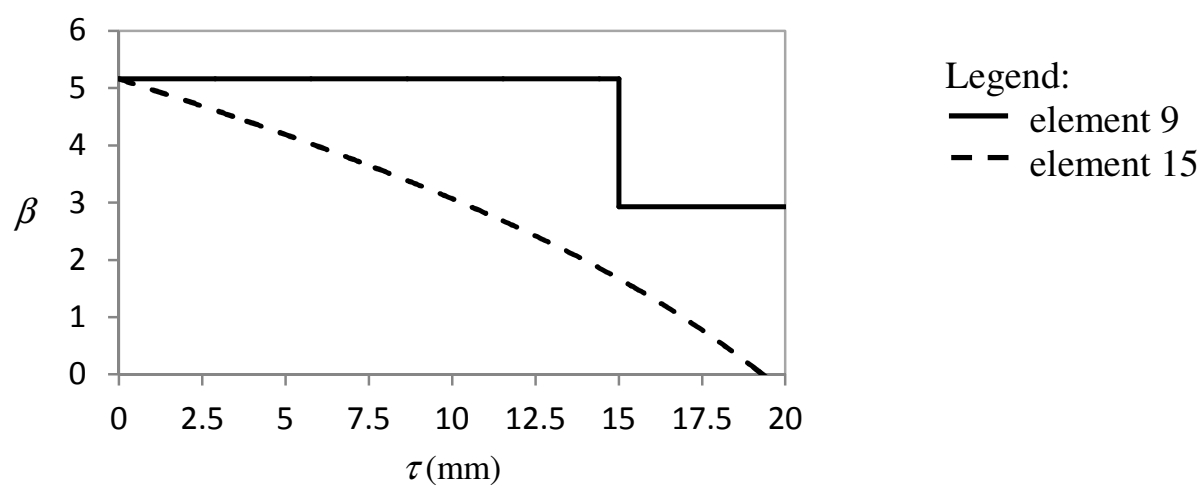

Figure 17 - System reliability index with reference time one year with respect to perimetral loss of cross section for element: 9 - continuous line; element 15 - dashed line.

From Figure 17 it is seen that the system reliability is more influenced by the loss of cross section of element 15 . When considering the loss of cross section of element 9, a sudden decrease of the system reliability is seen for $\tau=15 \mathrm{~mm}$ because element 9 has failed due to compression instability. Although the system reliability is always lower for the loss of cross section in element 15 , the decay process in element 9 may be considered more relevant since the same phenomena lead to a higher decrease in reliability in a specific defined period of the decay evolution $(\tau=15 \mathrm{~mm}$ corresponding to failure of element 9).

\section{SUMMARY AND CONCLUDING REMARKS}

This paper presents a framework for reliability assessment of existing timber structures using models updated with information of NDT that can be correlated with mechanical properties. For that purpose Bayesian methods were applied and three examples were presented: (i) a simply supported beam; (ii) a column; and (iii) a truss structure. In these examples, the structural reliability was calculated in the design and re-assessment phases, and the assessment of reliability regarding the design equations, through the used probabilistic approach and stochastic models, presented reliability levels in accordance with Eurocode standards.

After updating the resistance properties with NDT data, deterioration models were implemented. To assess the performance of an existing timber structure, in terms of reliability and time evolution, the mechanical properties and climatic conditions must be determined. In this case and regarding a Bayesian approach, different levels of prior information led to different reliabilities levels, meaning that reliability assessment regarding NDT data updating depends on the accuracy of each NDT and the respective degree of belief on the information.

When discussing the behavior of single element structures, it was shown how it is possible to update decay model parameters by use of NDT data through Bayesian methods. In this approach, different 
degrees of belief in the updating data resulted in significant differences in the evolution of reliability analysis. Moreover, regarding existing correlations from a database of NDT and laboratorial tests, the compressive strength parallel to grain of chestnut elements was determined using linear regression models obtained by Maximum Likelihood estimates, allowing the modeling of the uncertainty of each NDT.

Uncertainty related to physical parameters, as strength and geometric parameters, were considered in the reliability assessment. For compressive strength parallel to the grain, a Bayesian stochastic model is applied, where at a design stage the prior model is used for reliability assessment. In this paper, additional indicators are used to obtain the measured values for the physical variables. This introduces an additional model uncertainty which was estimated through the Maximum Likelihood method. For the reassessment stage, where data from NDT is available, the posterior model is used conditional to the measured values. Therefore, the reliability level could be both larger or smaller depending on the considered data, concluding that the objective of NDT data updating is to allow a better understanding of the characteristics of the structural elements, particularly with respect to the key elements of the structure, and to allow a more precise safety assessment. Epistemic uncertainty regarding statistical and measurement uncertainties can also be implemented to the applied Bayesian model, however were not considered in the paper.

Using NDT information as updating data in a probabilistic analysis, the results given by the pin penetration tests were similar to the reference experimental model with mean value and COV given by the results of the laboratorial tests. The resistance drilling and ultrasound updating schemes led to higher level of reliability than the reference model values, therefore these updating data should be considered with caution, as they can result in unsafe results for the reliability compared to the reference models.

In the truss structure example, the same design hypotheses led to different reliability levels regarding different timber strength classes. Identification of the key elements according to the type of load / action was demonstrated to be a fundamental step in order to understand the level of reliability of an existing structure. Although it is known that the decay rate is often dependant of the directional orientation of the decay surface, a perimetral loss of cross section was considered in the different members for obtaining the key elements of the truss structure regarding a decay process, as in this case the analysis is considered regarding the change of reliability in different members due to the loss of effective cross section. The compressive strength parallel to the grain was updated by use of NDT data and a reliability assessment was made with the cross section loss.

\section{ACKNOWLEDGMENTS}

The financial support of the Portuguese Science Foundation (Fundação para a Ciência e Tecnologia, FCT), through PhD Grant SFRH/BD/62326/2009, is gratefully acknowledged. 


\section{REFERENCES}

[1] Machado JS, Palma P. Non-destructive evaluation of the bending behaviour of in-service pine timber structural elements. Mater Struct 2011; 44:901-10.

[2] Branco JM, Piazza M, Cruz PJS. Structural analysis of two king-post timber trusses: Nondestructive evaluation and load-carrying tests. Constr Build Mater 2010; 24:371-83.

[3] Faggiano B, Grippa MR, Marzo A, Mazzolani FM. Experimental study for non-destructive mechanical evaluation of ancient chestnut timber. J Civ Struct Health Monit 2011; 1:103-12.

[4] Cavalli A, Togni M. How to improve the on-site MOE assessment of old timber beams combining NDT and visual strength grading. Nondestruct Test Eval 2013; DOI: 10.1080/10589759.2013.764424.

[5] Vega A, Dieste A, Guaita M. Modelling of the mechanical properties of Castanea sativa Mill. structural timber by a combination of non-destructive variables and visual grading parameters. Eur J Wood Prod 2012. DOI: 10.1007/s00107-012-0626-7.

[6] Bonamini G. Restoring timber structures - Inspection and evaluation. In: Timber Engineering STEP 2 - Design - Details and structural systems. Almere: Centrum Hout. The Netherlands; 1995, p. D3/1-9.ISBN: 9789056450021.

[7] Kasal B, Anthony RW. Advances in in situ evaluation of timber structures. Prog Struct Eng Mater 2004; 6:94-103.

[8] Drdáký M, Jirovský I, Slizková Z. On structural health and technological survey of historical timber structures. In: Tampone G (ed) Proceedings of the international conference Conservation of the historic wooden structures, Florence, 2005; 1:278-84.

[9] Hanhijärvi A, Ranta-Maunus A, Turk G. Potential of strength grading of timber with combined measurement techniques. Report of the Combigrade project - phase 1. Espoo. VTT publication no 568; 2005. ISBN: 9513866483.

[10] Calderoni C, De Matteis G, Giubileo C, Mazzolani FM. Experimental correlations between destructive and non-destructive tests on ancient timber elements. Eng Struct $2010 ; 32: 442-8$.

[11] Diamantidis D, editor. Probabilistic assessment of existing structures - a publication of the joint committee on structural safety (JCSS). RILEM Publications S.A.R.L The publishing Company of RILEM; 2001. ISBN: 9782912143242.

[12] Kasal B, Tannert T. In Situ Assessment of Structural Timber. Technical Committee 215-AST. RILEM State of the Art Reports, vol 7. RILEM Publications; 2010. ISBN: 9789400705593. 
[13] ISO 13822:2010. Bases for design of structures - Assessment of existing structures. Reference Number 13822:2010(E). Switzerland, International Organization for Standardization, 2010. 44 pp.

[14] ASCE 11-99. Guideline for Structural Condition Assessment of Existing Buildings. SEI/ASCE 11-99. American Society of Civil Engineers, 1999. 160 pp.

[15] UNI 11119:2004. Cultural heritage - Wooden artefacts - Load bearing structures of buildings On site inspection for the diagnosis of timber members. Milan, UNI, 2004. 9 pp. In Italian.

[16] UNI 11138:2004. Cultural heritage - Wooden artefacts - Load bearing structures of buildings Criteria for the preliminary evaluation, design and execution of works. Milan, UNI, 2004. 20 pp. In Italian.

[17] Cruz H, Yeomans D, Tsakanika E, Macchioni N, Jorissen A, Touza M, Mannucci M, Lourenço PB. Guidelines for the On-Site Assessment of Historic Timber Structures. Int J Archit Herit 2013; DOI: 10.1080/15583058.2013.774070.

[18] Wu HS, Zhong QP. Assessment for integrity of structures containing defects. Int J Pres Ves Pip 1998; 75:343-6.

[19] Das PC. Development of bridge-specific assessment and strengthening criteria. In: Das PC, editor. Safety of Bridges. Thomas Telford; 1997, p. 53-7. ISBN: 9780727725912.

[20] Shetty NK, Chubb MS, Manzocchi GME. Advanced methods of assessment for bridges. In: Das PC, editor. Management of Highway Structures. Thomas Telford; 1999, p. 13949. ISBN: 9780727727756.

[21] ISO 2394:1998. General Principles on Reliability for Structures. Reference Number 2394:1998. Switzerland, International Organization for Standardization, $1998.73 \mathrm{pp}$.

[22] EN 1990:2002. Eurocode 0: Basis of Structural Design. CEN European Committee for Standardization, 2002. 87 pp.

[23] Melchers RE. Structural Reliability Analysis and Prediction, UK, Chichester: John Wiley \& Sons; 1999. ISBN: 978-0471987710.

[24] Vrouwenvelder T. The JCSS probabilistic model code. Struct Saf 1997; 19:245-51.

[25] Faber MH, Köhler J, Sørensen JD. Probabilistic modeling of graded timber material properties. Struct Saf 2004; 26:295-309.

[26] Köhler J, Sørensen JD , Faber MH. Probabilistic modeling of timber structures. Struct Saf 2007; 29:255-67.

[27] JCSS. JCSS Probabilistic Model Code, Part 3: Resistance Models - 3.5 Properties of Timber. Probabilistic Model Code. Joint Committee on Structural Safety, 2006. ISBN: 9783909386796. 
[28] Honfi D, Mårtensson A, Thelandersson S. Reliability of beams according to Eurocodes in serviceability limit state. Eng Struct 2012; 35:48-54.

[29] Brites RD, Neves LC, Machado JS, Lourenço PB, Sousa HS. Reliability analysis of a timber truss system subjected to decay. Eng Struct 2013; 46:184-92.

[30] Lourenço PB, Sousa HS, Brites RD, Neves LC. In situ measured cross section geometry of old timber structures and its influence on structural safety. Mater Struct 2013; DOI: $10.1617 / \mathrm{s} 11527-012-9964-5$.

[31] Dietsch P, Kreuzinger H. Guideline on the assessment of timber structures: Summary. Eng Struct 2011; 33:2983-6.

[32] Lindley DV. Introduction to Probability and Statistics from a Bayesian Viewpoint, Part 2. Cambridge: Cambridge Univ. Press; 1970. ISBN: 9780521298667.

[33] Beck JL, Katafygiotis LS. Updating models and their uncertainties. I: Bayesian statistical framework. J Eng Mech 1998; 124:455-61.

[34] Katafygiotis LS, Beck JL. Updating models and their uncertainties. II: Model identifiability. J Eng Mech 1998; 124:463-7.

[35] Vanick MW, Beck JL, Au SK. Bayesian probabilistic approach to structural health monitoring. J Eng Mech 2000; 126:738-45.

[36] Mares C, Mottershead JE, Friswell MI. Stochastic model updating: Part 1 - theory and simulated example. Mech Syst Signal Pr 2006; 20:1674-95.

[37] Machado JS, Lourenço PB, Palma P. Assessment of the structural properties of timber members in situ - a probabilistic approach. In Proceedings of SHATIS'11 International Conference on Structural Health Assessment of Timber Structures, Lisbon, Portugal, 2011.

[38] Liñán CR, Conde MJM, Hita PR, Gálvez FP. The application of non-destructive techniques in the inspection of wooden structures of protected buildings: The case of Ntra. Sra. De Los Dolores Church (Isla Cristina, Huelva). Int J Archit Herit 2013; DOI: $10.1080 / 15583058.2013 .771292$.

[39] Feio AO, Lourenço PB, Machado JS. Non-Destructive Evaluation of the Mechanical Behavior of Chestnut Wood in Tension and Compression Parallel to Grain. Int J Archit Herit 2007; 1:27292.

[40] Elishakoff I. Safety Factors and Reliability: Friends or Foes?. Kluwer Academic Publishers, 2004. ISBN: 9781402017797.

[41] Wolfram J. Structural Safety and Reliability. UK, Edinburgh: Heriot-Watt University, 2004.

[42] Madsen HO, Krenk S, Lind NC. Methods of Structural Safety. Englewood Cliffs, NJ: PrenticeHall Inc., 1985. ISBN: 9780135794753. 
[43] Sørensen JD. PRADSS: Program for Reliability Analysis and Design of Structural Systems. Structural Reliability Theory, Paper No. 36, The University of Aalborg, Denmark, 1987.

[44] EN 1995-1-1:2004. Eurocode 5: design of timber structures. Part 1-1: General common rules and rules for buildings. CEN European Committee for Standardization, 2004. 123 pp.

[45] EN 338:2009. Structural timber - Strength classes. CEN European Committee for Standardization, 2009.

[46] Raiffa H, Schalifer R. Applied Statistical Decision Theory. Harvard University Press, Cambridge University Press, Cambridge, Mass., 1961.

[47] JCSS. Background documentation Eurocode, Part 1: Basis of Design. Joint Committee on Structural Safety, ECCS Publication 94. 1996.

[48] Kasal B. Estimate of the design values of the in-situ wood structural members based on semi-destructive experiments. In Proceedings of Conservation of the Historic Wooden Structures. Florence, Italy. February 23-27. 2005.

[49] JCSS. JCSS Probabilistic Model Code, Part 1: Basis of Design. Probabilistic Model. Joint Committee on Structural Safety, 2000. ISBN: 9783909386796.

[50] Stewart MG, Hong H. Structural reliability analysis and service life prediction for structural health monitoring. Structural Health Monitoring in Australia, T.H.T. Chan and D.P. Thambiratnam, eds., Nova Publishers, USA, 2011.

[51] Moore JC, Glenncross-Grant R, Mahini SS, Patterson R. Regional timber bridge girder reliability: Structural health monitoring and reliability strategies. Adv Struct Eng 2012; 15:793-806.

[52] Murta A, Varum H, Pinto J, Ramos L, Cunha V, Cardoso R, Nunes L. Aging effect on the integrity of traditional Portuguese timber roof structures. In: Proceedings of XII DBMC International Conference on Durability of Building Materials and Components, Porto, Portugal, April 12-15, 2011.

[53] Leicester RH. Engineered durability for timber construction. Prog Struct Eng Mater 2001; 3:21627.

[54] Wang C, Leicester R, Nguyen M. Probabilistic procedure for design of untreated timber poles inground under attack of decay fungi. Reliab Eng Syst Saf 2008; 93:476-81.

[55] Nguyen M, Leicester RH, Wang C, Foliente GC. A draft proposal for as1720.5: Timber service life design code. Forest \& Wood Products Australia. CSIRO, 2008.

[56] Leicester RH, Wang C, Nguyen M, Mackenzie CE. Design of exposed timber structures. Aust J Struct Eng 2009; 9:217-24.

[57] Hoffmeyer P, Sørensen JD. Duration of Load Revisited. Wood Sci Technol 2007; 41:687-711. 
[58] Rackwitz R. Optimization: the basis of code-making and reliability verification. Struct Saf 2000; 22:27-60.

[59] Vrouwenvelder T. Reliability based-code calibration The use of the JCSS Probabilistic Model Code. In Proceedings of JCSS Workshop on Code Calibration. Zurich, Switzerland. March 21-22. 2002.

[60] Vrouwenvelder ACWM. Developments towards full probabilistic design codes. Struct Saf 2002; 24:417-32. 